\title{
A Low Cost and Efficient Breast Cancer Detection Method With a Staircase Shaped Ultrawide Band Dielectric Resonator Antenna Using Monostatic Radar Based Microwave Imaging Technique
}

Gagandeep Kaur ( $\nabla$ gagandhindsa2127@gmail.com )

Thapar University: Thapar Institute of Engineering and Technology https://orcid.org/0000-0003-16591813

Amanpreet Kaur

Thapar University: Thapar Institute of Engineering and Technology

\section{Research Article}

Keywords: dielectric resonator antenna, phantom of human breast, beam-forming algorithm, 2D imaging, MATLAB

Posted Date: April 23rd, 2021

DOl: https://doi.org/10.21203/rs.3.rs-414407/v1

License: (c) (1) This work is licensed under a Creative Commons Attribution 4.0 International License.

Read Full License 


\title{
A low cost and efficient breast cancer detection method with a Staircase Shaped Ultrawide Band Dielectric Resonator Antenna using Monostatic Radar Based Microwave Imaging Technique
}

\author{
${ }^{1}$ Gagandeep Kaur and ${ }^{2}$ Amanpreet Kaur \\ 1. Ph.D.student,ECED, TIET, Patiala,2. Assistant Professor,ECED,TIET,Patiala
}

\begin{abstract}
In this article, a staircase shaped ultra-wide band dielectric resonator antenna (DRA) has been used as a sensor for detection of breast tumor by monostatic radar based microwave imaging (MRMWI).The proposed DRA has fractional bandwidth (BW) $98.5 \%$ and high peak gain 5.98dB along with dual polarization behavior from 5.12$8.2 \mathrm{GHz}$ and $11.02-13.8 \mathrm{GHz}$. In MRMWI setup, DRA is placed over the breast phantom at a distance of $7 \mathrm{~mm}$ and provides the safe exposure of radiation $(<1.6 \mathrm{~W} / \mathrm{Kg})$. For simulation, it rotates around the phantom at a fixed interval in elevation $\left(0-180^{\circ}\right)$ and azimuthal $\left(0-360^{\circ}\right)$ planes. It works as a radiate and receive the reflected signals towards and from the scanned area simultaneously. To validate the results, fabricated DRA is connected to vector network analyzer and rotates (as done for simulation) around the artificial breast phantom. That is a replica of human breast made from gelatin+sugar, Vaseline and wheat flour+water equivalent to skin, fat and tumor respectively. Afterward $\mathrm{S}_{11}$ responses are recorded in the presence and absence of tumor inside the phantom. A significant variation in recorded values leads to the detection of tumor that processed further in beam-forming algorithms; delay and sum (DAS) and delay-multiply and sum (DMAS) to reform 2-dimensional image of tumor in MATLAB.
\end{abstract}

Keywords: dielectric resonator antenna, phantom of human breast, beam-forming algorithm, 2D imaging, MATLAB.

Corresponding author:gagandhindsa2127@gmail.com, $\mathrm{Ph}:+919041939730$

\section{Intoduction}

Breast cancer is one of the most common diseases among the women. It usually happens when some cancerous or malignant cells start growing hysterically around the normal body cells [1].Many clinical techniques such as X-ray mammography, ultra sound and magnetic resonance imaging are available to detect the presence of the breast tumor[2]. But each technique has its own short-comings such as exposure of the ionized radiation along with painful, costly and time consuming treatment etc [3]. For early stage breast cancer screening, one of the most promising techniques is microwave imaging (MWI) and it is gaining the attention of numerous researchers. This technique having some advantages such as it is simple, non-ionizing exposure along with un-obstructive, inexpensive and high image resolution of the scanned body area. The basic principle of MWI is based on the large deviation in dielectric properties of malignant and healthy cells [4-5].It is mainly classified into two types i.e. monostatic and multi-static MWI. In monostatic MWI, single antenna is placed over the phantom to transmit and receive the signals[6]. Similarly in multistaic MWI, numerous antennas are placed around the phantom in the form of array that makes it quite complex and a time consuming method [7].The procedure followed for MRMWI is simple, speedy and affordable as compared to multistaic MWI. Thus monostatic MWI method is opted for the breast tumor detection.

In MRMWI, antenna is worked as a sensor and it needs some specific characteristics as wide bandwidth with multiple resonances, high peak gain, moderately directional radiation pattern and power coupling to the phantom that not have any effect on the healthy cells[8].For this aspect, a staircase DRA with overall volume of $4252.5 \mathrm{~mm}^{3}(25 \mathrm{~mm} \times 30 \mathrm{~mm} \times 5.67 \mathrm{~mm})$ has been proposed for breast tumor detection using MRMWI technique. The proposed DRA shows an ultra-wideband(UWB)characteristics with $5.1-15 \mathrm{GHz}$ of operating frequency range that has been designed (in CST) and fabricated (using photolithography) on a FR4 substrate of $1.57 \mathrm{~mm}$ thickness. On top and bottom of the substrate a layer of copper is deposited as a feedline and a ground plane respectively. As a final point staircase dielectric resonator (DR) of alumina with $4 \mathrm{~mm}$ thickness is placed over the feedline. This DRA is works as a sensor that radiate non-ionizing emissions with safe exposure of radiation $(<1.6 \mathrm{~W} / \mathrm{Kg}$ for $1 \mathrm{~g}$ of body tissue) [9] on the phantom in two cases; in presence and absence of tumor (radius $=5 \mathrm{~mm}$ ) inside the breast phantom. Furthermore backscattered signals are recorded by the same DRA (mono-statically) in terms of reflection coefficient at different positions by rotating it around the breast phantom from $0-180^{\circ}$ in elevation and $0-360^{\circ}$ in azimuthal planes with fixed interval of $10^{\circ}$. These backscattered signals are used to identify the morphological changes in biological tissues and its position due to the presence of a tumor. For this purpose the beam-forming algorithms i.e. DAS and DMAS are applied on the resultant backscattered signals to reconstruct a 2Dimage of the scanned breast area using MATLAB R2018a. 


\section{Different layers of the proposed DRA's geometry and design procedure}

For the detection of breast tumor using MRMWI system, some important requirements for an antenna are that it should be cover wide-band with multiple resonance frequencies, high peak gain, dual polarization behavior and better resolution power. In order to achieve the above mentioned requirements a staircase shaped UWB DRA has been proposed. It is designed and simulated in CST version 2016 with impedance bandwidth of 9.9GHz (5.1$15 \mathrm{GHz}$ ), peak gain of $5.98 \mathrm{~dB}$ and elliptical polarization properties. It has four different layers i.e. ground plane followed by substrate $(25 \mathrm{~mm} \times 30 \mathrm{~mm})$, feedline and dielectric resonator (DR). The proposed prototype is printed on a FR4 lossy substrate $\left(\varepsilon_{\mathrm{r}}=4.4, \mathrm{~h}=1.57 \mathrm{~mm}\right)$. On the top and base of this substrate a layer of copper material $(35 \mu \mathrm{m})$ is deposited to use as a feedline and ground plane respectively as depicts in figure 1(b) and 1(c) respectively. As a final point, a staircase DR of alumina $\left(\varepsilon_{\mathrm{r}}=9.8, \mathrm{~h}=4 \mathrm{~mm}\right)$ is placed over the feed point to used as a patch as shown in figure 1(a).In figure 1(a to $\mathrm{c}$ ), the black section represents the copper, grey represents the FR4 and dark yellow colour represents the alumina.To enhance the performance of the DRA in terms of bandwidth, return loss and axial ratio, the geometry of the antenna is optimized by using defective ground structure (DGS) technique, adding tuning stubs and by modifying DR's shape as explained with details in next section 3. The final optimized dimensions of the proposed antenna are specified in table 1 .

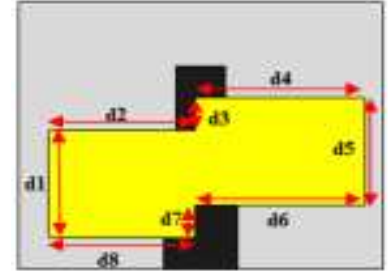

(a)

(b)

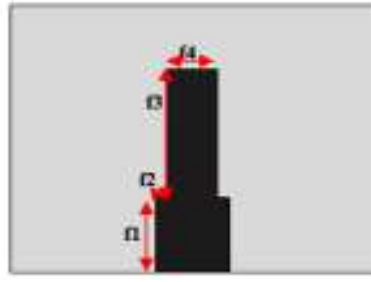

(c)

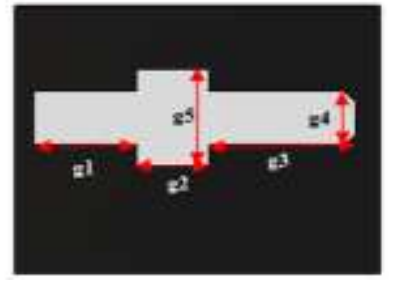

Figure 1: Different layers of the proposed DRA(a) Top view along with DR (b) Feedline(c) Ground plane

Table 1: Optimization parameter and its values

\begin{tabular}{|l|l|l|l|l|l|l|l|l|l|l|l|l|l|}
\hline Specification & $\mathrm{d} 1=\mathrm{d} 5$ & $\mathrm{~d} 2=\mathrm{d} 8$ & $\mathrm{~d} 3=\mathrm{d} 7$ & $\mathrm{~d} 4=\mathrm{d} 6$ & $\mathrm{f} 1$ & $\mathrm{f} 2$ & $\mathrm{f3}$ & $\mathrm{f} 4$ & $\mathrm{~g} 1$ & $\mathrm{~g} 2$ & $\mathrm{~g} 3$ & $\mathrm{~g} 4$ & $\mathrm{~g} 5$ \\
\hline values $(\mathrm{mm})$ & 10 & 12 & 3 & 14 & 7 & 1 & 12 & 4 & 8.5 & 6 & 12 & 5 & 9 \\
\hline
\end{tabular}

\subsection{Design procedure and simulation performance of the proposed DRA}

The main objective of the present research work is to initially attain an UWB characteristics from a proposed staircase shaped DRA that is modified with rectangular tuning stubs and defected ground structure (DGS). Furthermore, the proposed UWB DRA used as a sensor that identify the presence of the breast tumor of $5 \mathrm{~mm}$. This section gives a complete details about their intermediate steps followed to achieve the desired UWB $(5.1-15 \mathrm{GHz})$ responses as shown in figure 2 . And their corresponding responses in terms of S-parameters and axial ratio (AR) are as depicted in figure 3 and 4 respectively.

- The initial dimension of the rectangular DR i.e. $13 \mathrm{~mm} \times 26 \mathrm{~mm}$ has been chosen by considering the dielectric waveguide model (DWM) as given in equation 1[10].

$\mathrm{f}_{\mathrm{mnl}}=\frac{\mathrm{c}}{2 \pi \sqrt{\varepsilon_{\mathrm{r}}}} \sqrt{\mathrm{k}_{\mathrm{x}}^{2}+\mathrm{k}_{\mathrm{y}}^{2}+\mathrm{k}_{\mathrm{z}}^{2}}$

Where $\mathrm{k}_{\mathrm{x}}=\mathrm{m} \pi /(\mathrm{d} 2+\mathrm{d} 4), \mathrm{k}_{\mathrm{y}}=\mathrm{n} \pi /(\mathrm{d} 1+\mathrm{d} 3)$ and $\mathrm{k}_{\mathrm{z}}=1 \pi / 2 \mathrm{~d}$ represents the wave number along $\mathrm{x}, \mathrm{y}$ and $\mathrm{z}$ axis respectively. For the proposed DRA the values of $\mathrm{d} 1=10 \mathrm{~mm}, \mathrm{~d} 2=12 \mathrm{~mm}, \mathrm{~d} 3=3 \mathrm{~mm}, \mathrm{~d} 4=14 \mathrm{~mm}, \mathrm{~d}=4 \mathrm{~mm}, \mathrm{~m} / \mathrm{n} / \mathrm{l}=1$ and gets the resonant frequency of $7.2 \mathrm{GHz}$ that is relatively close to the simulated resonant frequency of $8.05 \mathrm{GHz}$.

- The conventional DRA geometry (DRA1) along with rectangular DR, simple microstrip feed and full ground plane $\left(25 \times 30 \mathrm{~mm}^{2}\right)$ excites the tri-band operations i.e. $7.65-8.22 \mathrm{GHz}, 9.35-9.92 \mathrm{GHz}$ and $13.2-$ $15.2 \mathrm{GHz}(\mathrm{BW}=27.1 \%)$ as shown in figure 3 (dotted blue color plot). The DRA1 geometry provides the entirely linear polarization (AR above $10 \mathrm{~dB}$ ) except for 6.8 and $11.4 \mathrm{GHz}$ of frequency.

- To improve the fractional bandwidth, return loss and AR of the conventional antenna, two rectangular stubs each of dimension $7 \mathrm{~mm} \times 1 \mathrm{~mm}$ are joined on both sides of feedline (geometry DRA2). By these slots the total volume $1.352 \mathrm{~cm}^{3}$ of DR reduces to $1.068 \mathrm{~cm}^{3}$ (21\% reduction of the total volume) and also reduction in Q-factor. This leads to the improvement in operational bandwidth and allows it to excite two additional frequency bands from 
10.71-11.3GHz,11.77-12.1GHz along with $7.65-8.22 \mathrm{GHz}, 9.3-10.14 \mathrm{GHz}$, and $13.2-16.2 \mathrm{GHz} \quad(\mathrm{BW}=44.6 \%)$ frequency bands as shown in figure 3 (dotted red color plot).By DRA2 geometry the antenna provides the AR $<10 \mathrm{~dB}$ for two sub-bands i.e. $7.86-8.2 \mathrm{GHz}$ and $9.6-10.02 \mathrm{GHz}$.

- After that, the shape of the rectangular DR is modified into staircase shaped by etching two rectangular slots each of dimensions $12 \mathrm{~mm} \times 3 \mathrm{~mm}$ from its corners as shown in figure 2 (geometry DRA3). Through these alternations the antenna provides multiple bands of $7.9-8.92 \mathrm{GHz}, 10.71-12.1 \mathrm{GHz}, 12.7-14.7 \mathrm{GHz}, 14.7-16.2 \mathrm{GHz}$ with wider bandwidth $(\mathrm{BW}=49 \%)$ as shown in figure 3(dotted green color plot). DRA3 geometry also offers the excellent improvement in the AR from $7-8.8 \mathrm{GHz}$ and $11.2-14 \mathrm{GHz}$.

- Finally to get an UWB and dual polarization behavior, the geometry of the ground plane is modified by using DGS technique. That disturbs the total current distribution and helps in decreasing the size of the DRA. The proposed DRA4 geometry allows the antenna to excite desired UWB characteristics from 5.1-15GHz $(\mathrm{BW}=98.5 \%)$ as depicted in figure 3(solid pink color plot). The AR of the DRA4 is also improved significantly from $5.12-8.2 \mathrm{GHz}$ and $11.02-13.8 \mathrm{GHz}$.
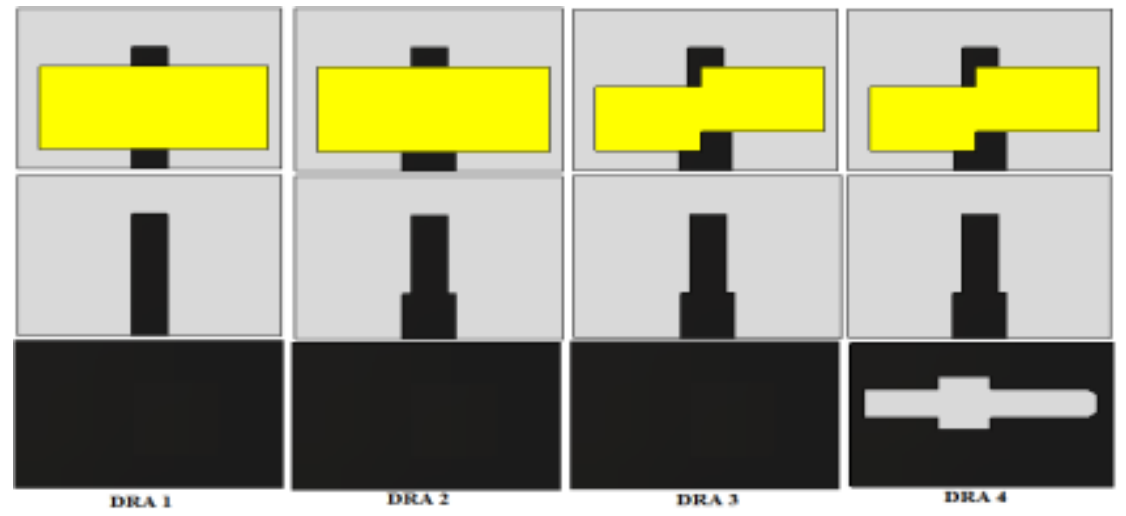

Figure 2: Intermediate geometry of the DRA

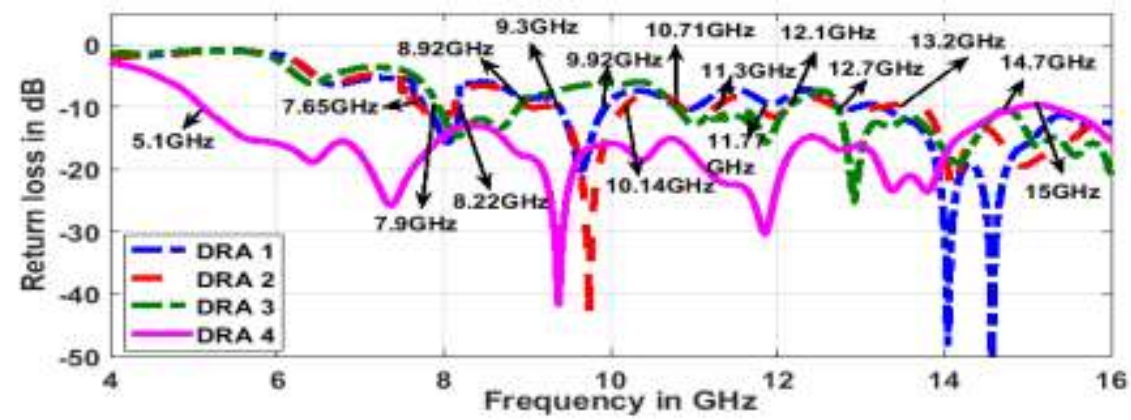

Figure 3: S-parameter responses corresponding to DRA geometries as shows in figure2

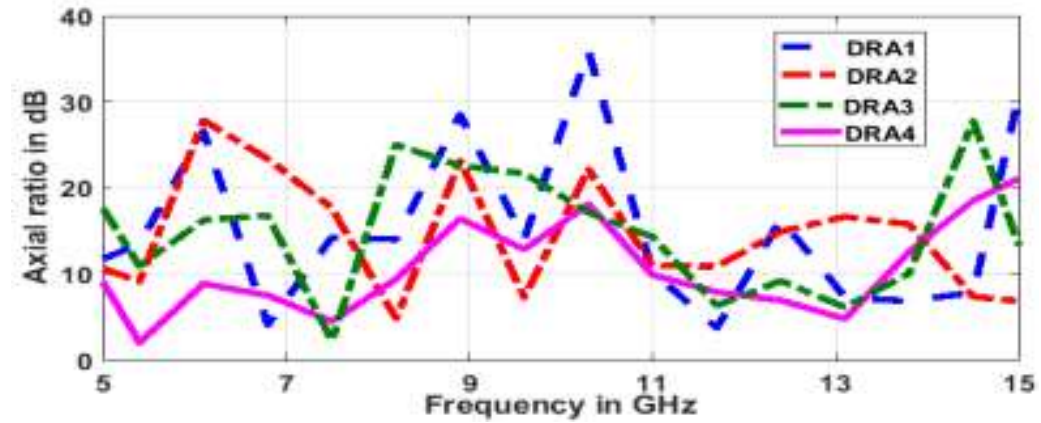

\section{DRA operations}

Figure 4: Comparison plot in terms of axial ratio

\subsection{Validation of field modes of the proposed DRA}


While radiation the proposed stair case shaped DRA proficiently exhibit a fundamental mode i.e. $\mathrm{TE}_{111}$ andthree higher ordermodesi.e. $\mathrm{TE}_{211}$ and $\mathrm{TE}_{221}$ in $\mathrm{XZ}$ and $\mathrm{YZ}$ planes. The different modes are calculated by equation 1 at the resonant frequencies i.e. 7.2, 8.2 and 10.6while the simulated resonant frequencies are 8.05, 9.1 and 11.2 for different modes such as $\mathrm{TE}_{111}, \mathrm{TE}_{211}$ and $\mathrm{TE}_{221}$ respectively. Figure 5(a) shows an E-filed distribution of the dominant modeTE $111^{\mathrm{x}}$ and $\mathrm{TE}_{111^{\mathrm{y}}}$ as $19378 \mathrm{~V} / \mathrm{m}$ and $22977 \mathrm{~V} / \mathrm{m}$ at the frequencies of $8.05 \mathrm{and} 8.52 \mathrm{GHz}$ respectively. Figures 5(b) shows E-field distribution of $22262 \mathrm{~V} / \mathrm{m}\left(\mathrm{TE}_{211^{\mathrm{x}}}\right)$ and $23554 \mathrm{~V} / \mathrm{m}\left(\mathrm{TE}_{211^{\mathrm{x}}}{ }^{\mathrm{x}}\right)$ at frequencies of $9.1 \mathrm{GHz}$ and $9.37 \mathrm{GHz}$ respectively. Figures 5(c) show E-field of $26339 \mathrm{~V} / \mathrm{m}\left(\mathrm{TE}_{221}{ }^{\mathrm{x}}\right)$ and $21414 \mathrm{~V} / \mathrm{m}\left(\mathrm{TE}_{221^{\mathrm{y}}}\right)$ at the frequencies of 11.2 and $11.8 \mathrm{GHz}$ respectively that leads to the generation of dual polarization behavior(AR $<10 \mathrm{~dB})$ by proposed DRA for the frequency band $5.12-8.2 \mathrm{GHz}$ and $11.02-13.8 \mathrm{GHz}$.
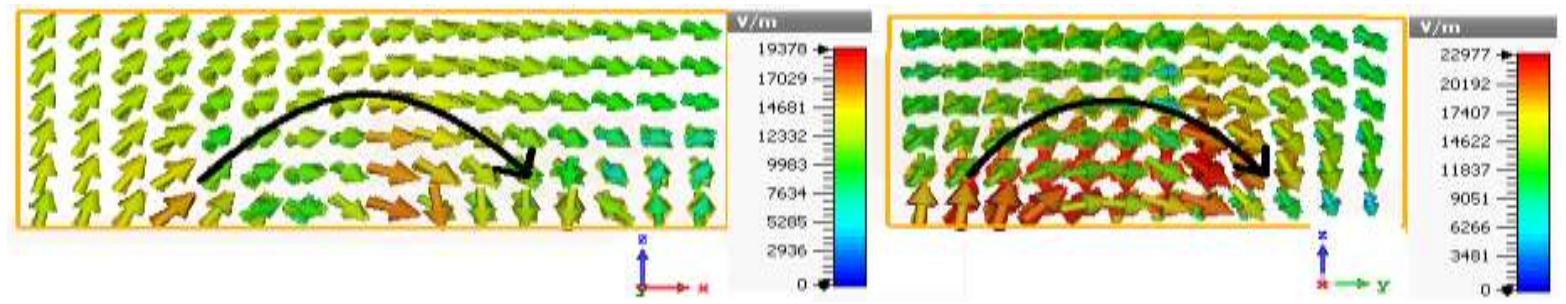

(a)
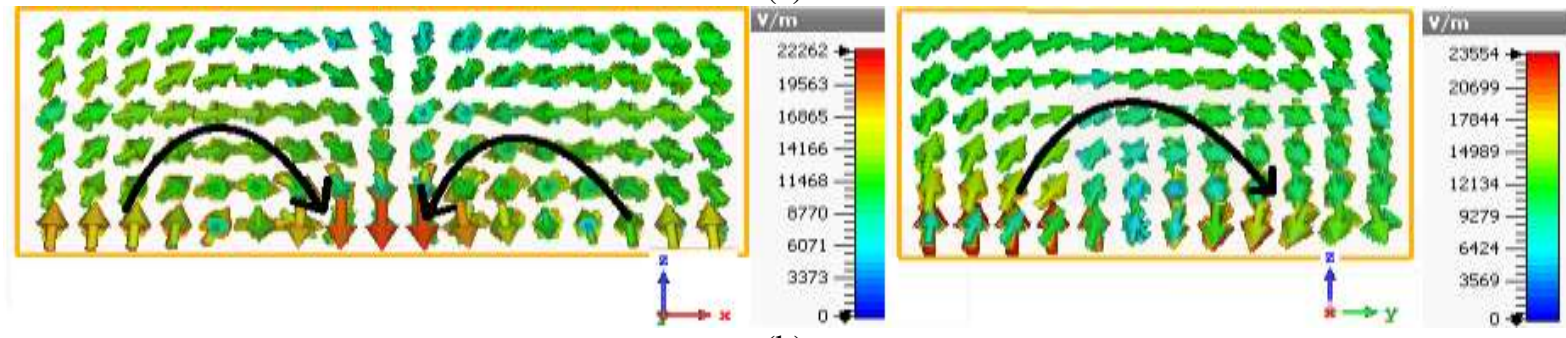

(b)
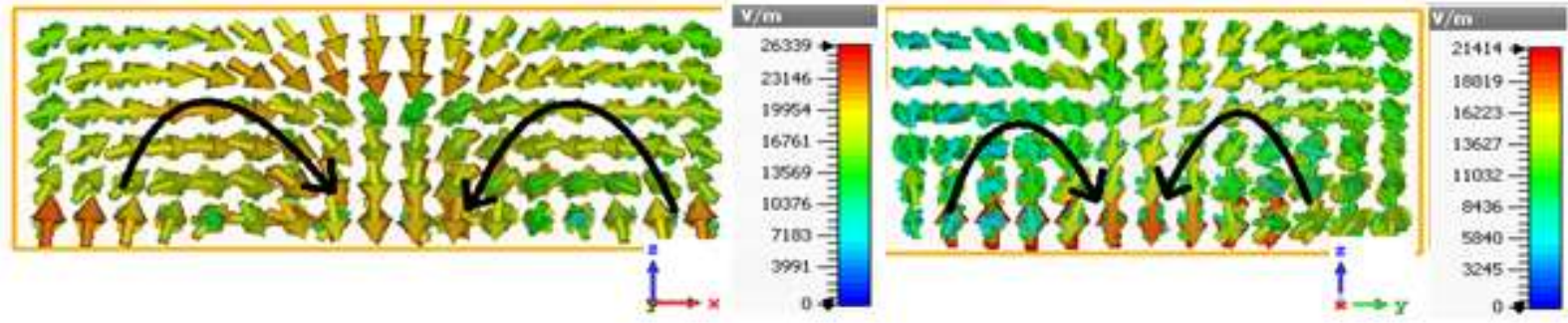

(c)

Figure 5: E-field distribution plot in $\mathrm{XZ}$ and $\mathrm{YZ}$ planes for different operating modes (a)TE $\mathrm{TE}_{111}(\mathrm{~b}) \mathrm{TE}_{211}(\mathrm{c}) \mathrm{TE}_{221}$

\section{Fabrication and testing of the proposed DRA}

For practical testing of breast tumor detection, primarily DRA is fabricated using wet etching photolithography process . The proposed prototype consists a layer of FR4 lossy substrate. On the top and bottom of this substrate, a feedline and a ground structure (DGS) of copper material are deposited as shown in figure 6(b) and 6(c) respectively. At lasts a staircase shaped DR of material alumina (cut using water jet cutting technique) is staked over the feedline with the help of panacol vitralit as shown in figure 6(a).For the validation and testing of the results, a SMA female connector is soldered at the termination point of the feedline for activation purpose. After that, SMA connector is allied to the vector network analyzer's (VNA) probe through coaxial cable of 50ohms impedance. Figure 7(a) shows the variation among simulated (solid blue plot) and measured (dotted pink plot) $S_{11}$ parameter. It indicates that the proposed DRA effectively shows UWB characteristics from $5.1-15 \mathrm{GHz}$ for simulated and 5.38 $12.3 \mathrm{GHz}, 12.52-13.2 \mathrm{GHz}$ and $13.54-14.2 \mathrm{GHz}$ for measured case and gets approximately $84 \%$ matching between them. Figure 7(b) shows the Snapshot of the measured S-parameter on VNA screen. Next subsection 4.1 and 4.2 explained brief summary of the broadband gain and polar plot of the proposed antenna. 


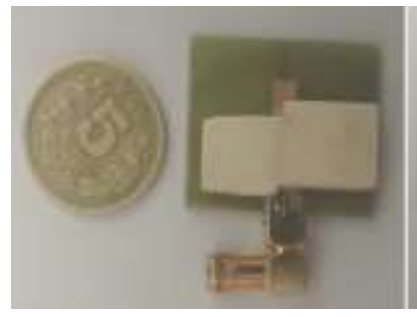

(a) (b)
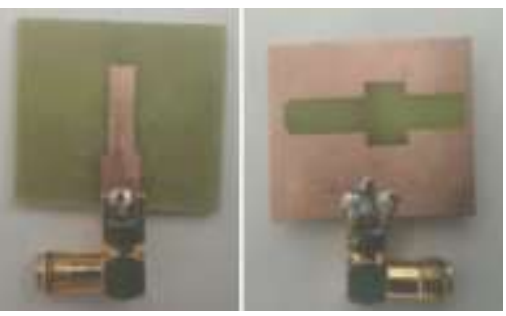

(c)

Figure 6: Fabricated prototype (a) Staircase DR (b) Feedline (c) Ground structure

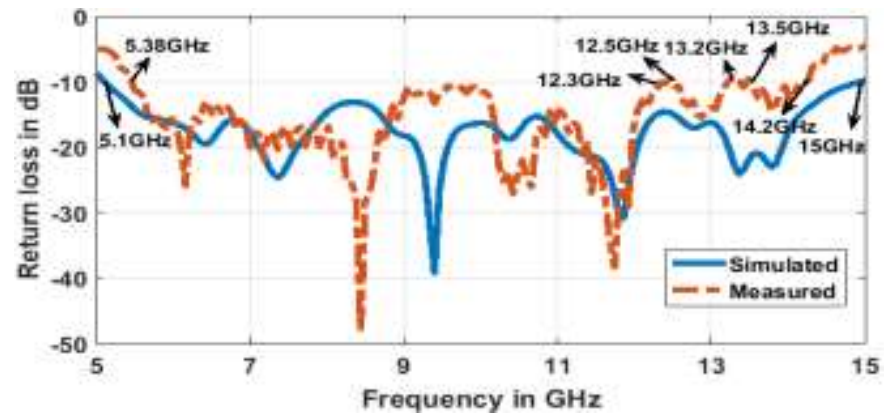

(a) (b)

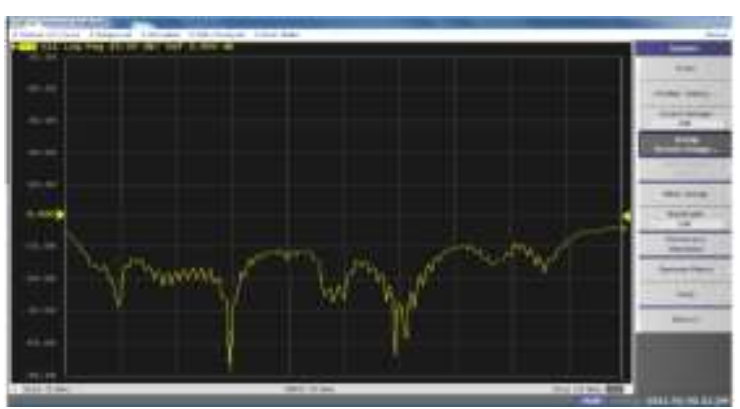

(b) Snapshot of $\mathrm{S}_{11}$ on VNA

\subsection{Broadband gain}

The combined broadband gain plots for simulated and measured values is depicts in figure 8 . The proposed DRA achieved the simulated gain $5.98 \mathrm{~dB}$ and measured gain $6.05 \mathrm{~dB}$ at $7.3 \mathrm{GHz}$ and $7.52 \mathrm{GHz}$ frequency respectively. The DRA shows an average gain of $4.5 \mathrm{~dB}$ (simulated) and $4.58 \mathrm{~dB}$ (measured). Thus the proposed DRA is an appropriate choice for the biomedical applications i.e. breast tumor detection

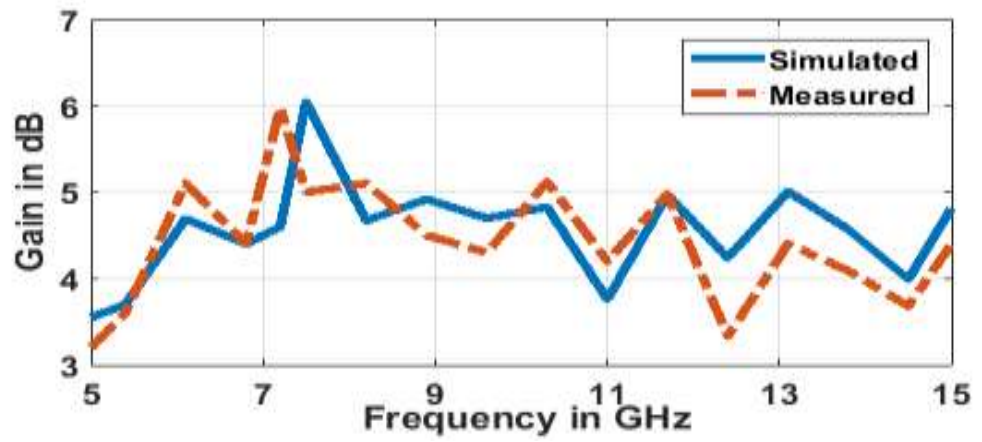

Figure 8: Combined plot of simulated and measured results in terms of gain

\subsection{Polar radiation pattern}

The2D polar plot radiation patterns are experimentally measured by placing the proposed DRA (in XZ and YZ plane) inside an anechoic chamber. For this measurement setup, a horn antenna (transmitter) is placed at a distance of $100 \mathrm{~cm}$ from the proposed DRA (receiver), and the results in the form of polar plots are observed on VNA. Additionally the polar plot of simulated and experimentally measured results at three main resonant frequencies of 7.3, 9.37 and $11.8 \mathrm{GHz}$ (return loss $>-25 \mathrm{~dB}$ ) are depicts in Figure 9(a-c) respectively. The 2D polar plot of the proposed staircase shaped DRA is bi-directional that is an appropriate selection for the detection of breast tumor. 


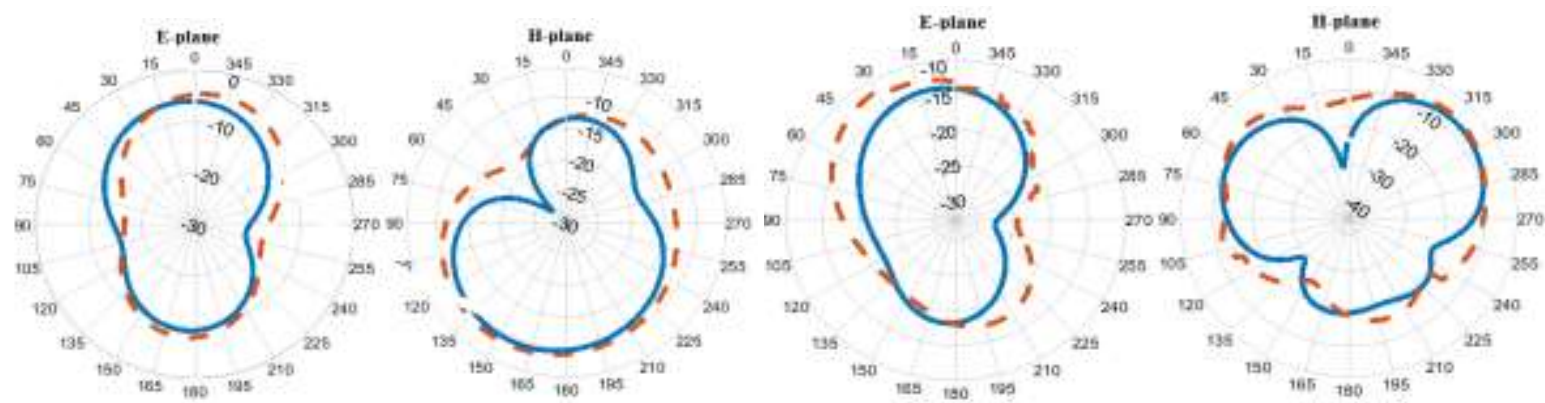

(a) (b)

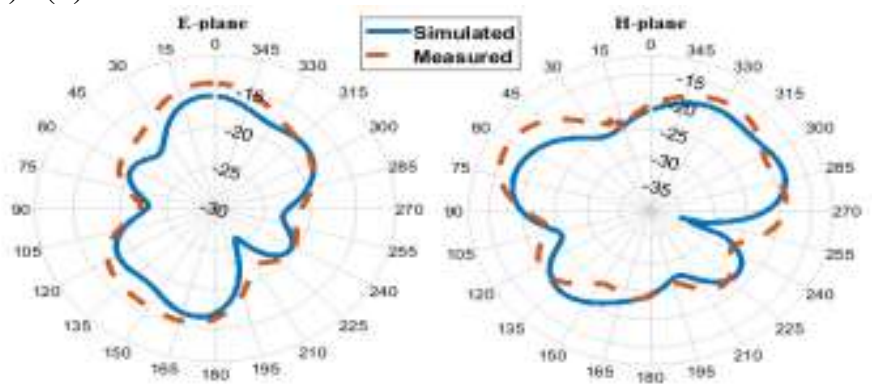

(c)

Figure 9: Radiation properties in $\mathrm{E}$ and $\mathrm{H}$ plane at resonant frequencies of (a) $7.3 \mathrm{GHz}$ (b) $9.37 \mathrm{GHz}$ (c) $11.8 \mathrm{GHz}$

\section{Microwave Imaging Procedure for the detection of breast cancer}

The hemispherical mimic of breast phantom is designed with similar electrical properties as that of human breast and simulated in CST version 2016 to detect the tumor inside it. The total volume of the breast phantom is around $16,747 \mathrm{~mm}^{3}$ with total radius $\mathrm{r} 3=20 \mathrm{~mm}$ and has three layers skin $(2 \mathrm{~mm})$ followed by fat $(\mathrm{r} 2=18 \mathrm{~mm})$ and tumor $(\mathrm{r} 1=4 \mathrm{~mm})$ as shown in figure 10(a). In MRMWI the proposed DRA is placed over the breast phantom at distance D and it rotates in both azimuthal and elevation plane are shown in figure $10 \mathrm{~b}$ and $10 \mathrm{c}$ respectively. When $\mathrm{D}$ is $7 \mathrm{~mm}$, it provides the safe exposure of the radiation with specific absorption rate (SAR) is $1.53 \mathrm{~W} / \mathrm{Kg}$ for $1 \mathrm{~g}$ of tissue at simulated resonant frequency of $9.37 \mathrm{GHz}$ but with $\mathrm{D}<7 \mathrm{~mm}$ the SAR is varies from $1.73-15.8 \mathrm{~W} / \mathrm{Kg}$.
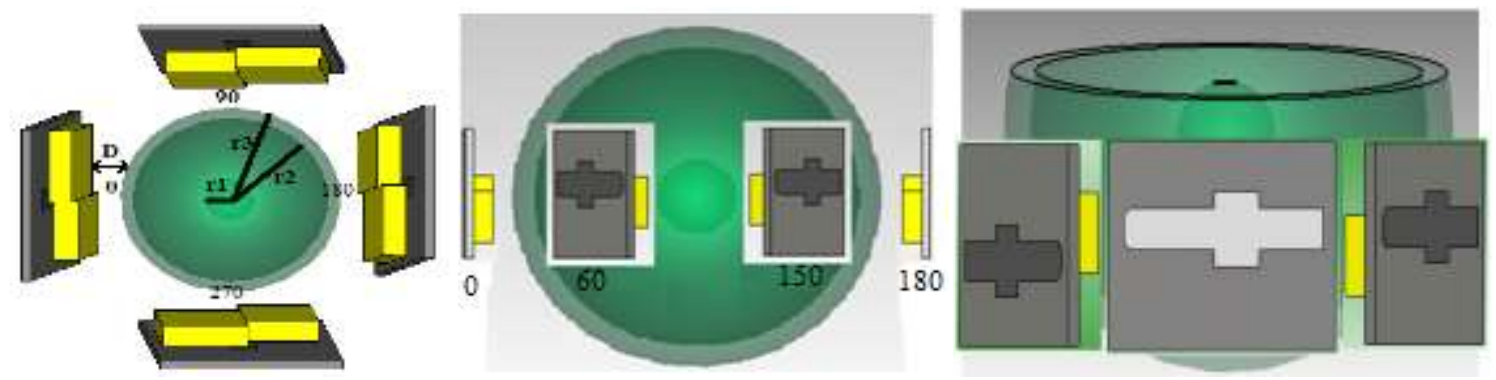

(a) (b)(c)

Figure 10: Placement of the antenna around phantom (a) Top view (b) Elevation plane(c) Azimuthal plane

For practical testing, the breast phantom model is made artificially from crystalline gelatin + sugar like skin $\left(\varepsilon_{r}=45-\right.$ $\left.65, \sigma=5-20 \mathrm{Sm}^{-1}\right)$, petroleum jelly like fat $\left(\varepsilon_{r}=2.36, \sigma=0.0012 \mathrm{Sm}^{-1}\right)$ and wheat-flour + water like tumor $\left(\varepsilon_{r}=23\right.$, $\left.\sigma=2.57 \mathrm{Sm}^{-1}\right)[11]$ as shown in figure 11(a).For the validation of results (S-parameter), the fabricated DRA is coupled to the VNA and rotates around the artificial breast phantom in same approach as that done for simulation in CST (azimuthal plane from $0-360^{\circ}$ and in elevation plane from $0-180^{\circ}$ ) as depicts in figure 11(b).Figure 12(a) and 12(b) shows the simulated and measured S-parameter comparison plot for the two cases: with (dotted orange curve) and without (solid sky blue curve) placement of tumor. The noticeable deviation in S-parameter at resonant 
frequencies of $6.2,8.5,10.2,12.13$ and $13 \mathrm{GHz}$ for simulated and $6,7.56,9.7,11.8$ and $13 \mathrm{GHz}$ for measured has been observed. Thus from this it is concluded that the reflection coefficient with presence of tumor (black color) is shifted upward due to high water content in tumor.
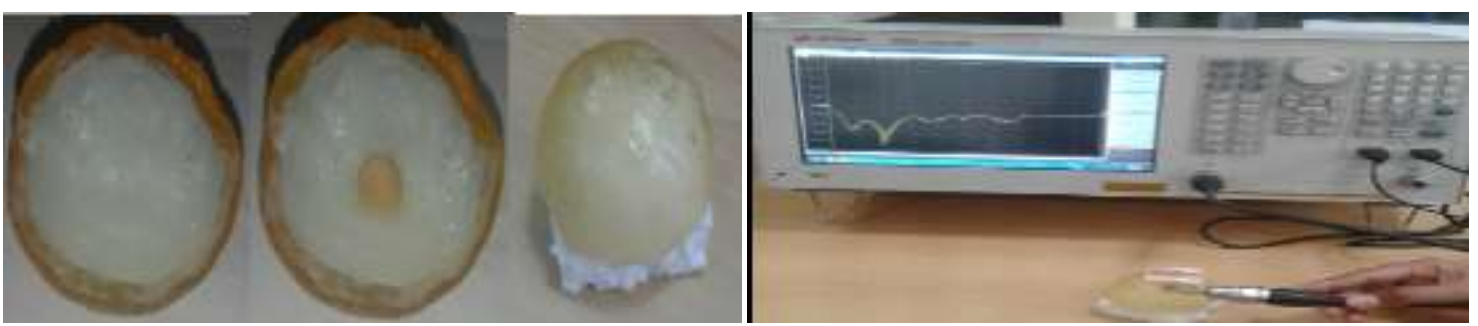

(a) (b)

Figure 11: (a) Artificial breast phantom with and without placement of tumor (b) Testing on the VNA by placing DRA over the phantom

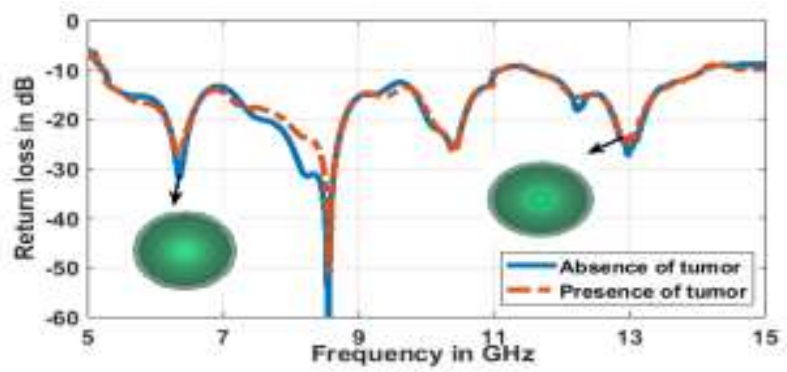

(a)

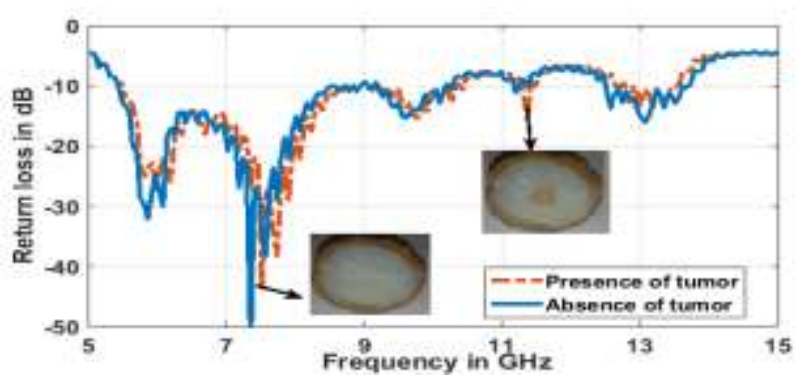

(b)

Figure 12: S-parameters comparison plot with presence and absence of tumor (a) Simulated (b) Measured Results

The recorded backscattered signals $\left(\mathrm{S}_{11}\right)$ mainly consist of strong reflections from tumor and also from skin and fat. For the identification of tumor, there is a need to eliminate the unwanted reflections i.e. from skin and fat. Thus for this purpose we opt subtraction method as given in equation (2) [12]. In this method, a tumor of $5 \mathrm{~mm}$ is inserted in the phantom at $(0,0)$ coordinates and reflections are recorded at each position as Reflection coefficient ${ }^{\text {with tumor }}{ }^{\text {. Then }}$ reflections are recorded without placing any tumor in breast phantom as Reflection coefficient without tumor

Reflection-coefficient $(\mathrm{x}, \mathrm{y})=$ Reflection-coefficient $^{\text {with-tumor }}(\mathrm{x}, \mathrm{y})$-Reflection-coefficient ${ }^{\text {with-tumor }}(\mathrm{x}, \mathrm{y})$

These results are utilized in different beam-forming algorithms to get a clear 2D image of the breast tumor cell. The next subsections illustrate the use of this data in two main image reconstruction algorithms. But the subtraction method is not practically feasible to identify the location of the tumor. There is several interference removal algorithms have been developed to find out the size and position tumor.

\subsection{Measured results with an artificial breast phantom}

\subsubsection{Delay and sum (DAS)}

The mathematical formula for the DAS algorithm is given in equation 3 [13]. In this algorithm, firstly the received $\mathrm{S}$-parameter is recorded at individual antenna positions by rotating it around the breast phantom. Then time-delays for all received Reflection-coefficient (x,y) are calculated based on position of transmitter and receiver antenna, these time delayed signals are summed up as $\mathrm{S}(\mathrm{t})$. The $\mathrm{S}$-parameters where there is a good difference between the values of with and without tumor which actually represents the reflections from any malignant cells are added coherently (because the signals gets from tumor has same frequency and phase so their addition give rise to a high peak signals as focus point at particular frequency) and the reflections from normal cells are added incoherently (because of different phase and frequency they may cancel out after addition). Therefore the energy or intensity of the $S(t)$ parameter values from tumor affected area gets amplified compared to the normal skin reflections at frequencies of 5.98, 7.6, 9.58, 11.75 and $13 \mathrm{GHz}$ because adding coherent signals will raise the intensity level. But a 
very minor difference in intensity level of skin and tumor's reflection coefficients particularly at frequency $5.98,11.75$ and $13 \mathrm{GHz}$ and maximum at $7.6 \mathrm{GHz}$ as illustrated in figure 13(a).The process is repeated for all the focal points within the breast phantom and final image of breast tumor is plotted using MATLAB in X-y plane as shown in figure 13(b). And observed that radius of the detected tumor is around $4 \mathrm{~mm}$ at coordinate $(-1,-1.5)$.
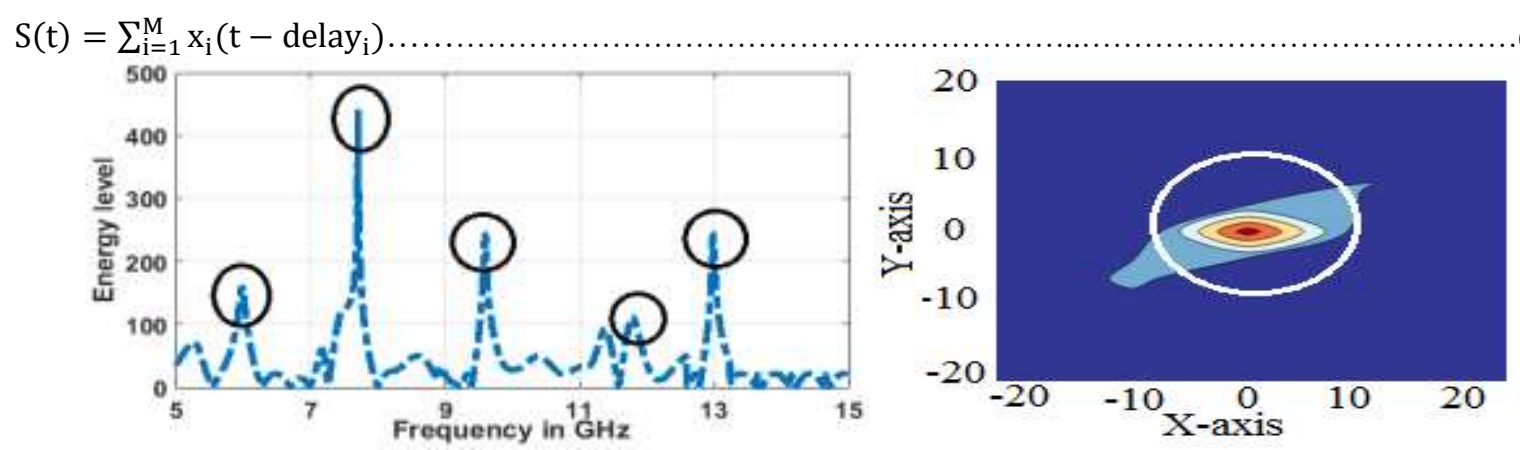

Figure 13: By DAS algorithm (a) Energy versus frequency plot (b) Image reconstructed in x-y plane

\subsubsection{Delay multiply and sum (DMAS)}

DMAS has more contrast, low side lobes and better resolution than DAS. The DMAS method uses summation of pair wise multiplications of signals to estimate scattered energy profile as mentioned in equation 4 [13]. For each focal point, time alignment synthetically focuses received signals at that point. The resultant signals are used to reconstruct the 2D image of breast tumor with enhanced quality at particular frequency 7.6GHzas depicted in figure 14(a) using equation 4. It is observed that energy level at this frequency is much improved from 450 to $1500 \mathrm{~dB}$ and. But at the other frequency values the energy level is reduced i.e. less than $300 \mathrm{~dB}$ and gets only one amplified tumorous signal. That helps in the reconstruction of 2Dand offers the approximate position $(0,-1)$ and radius of the breast tumor $4.23 \mathrm{~mm}$. The $2 \mathrm{D}$ microwave image is reconstructed to get a clue about the position of the breast phantom as shown in figure 14(a).

$$
\mathrm{Y}(\mathrm{t})=\sum_{\mathrm{i}=1}^{\mathrm{M}-1} \sum_{\mathrm{j}=\mathrm{i}+1}^{\mathrm{M}} \mathrm{x}_{\mathrm{i}}\left(\mathrm{t}-\text { delay }_{\mathrm{i}}\right) * \mathrm{x}_{\mathrm{j}}\left(\mathrm{t}-\Delta \text { delay }_{\mathrm{j}}\right)
$$

Where $\mathrm{M}$ is number of antenna rotation, $\mathrm{i}$ and $\mathrm{j}$ are represent the different position of antenna.
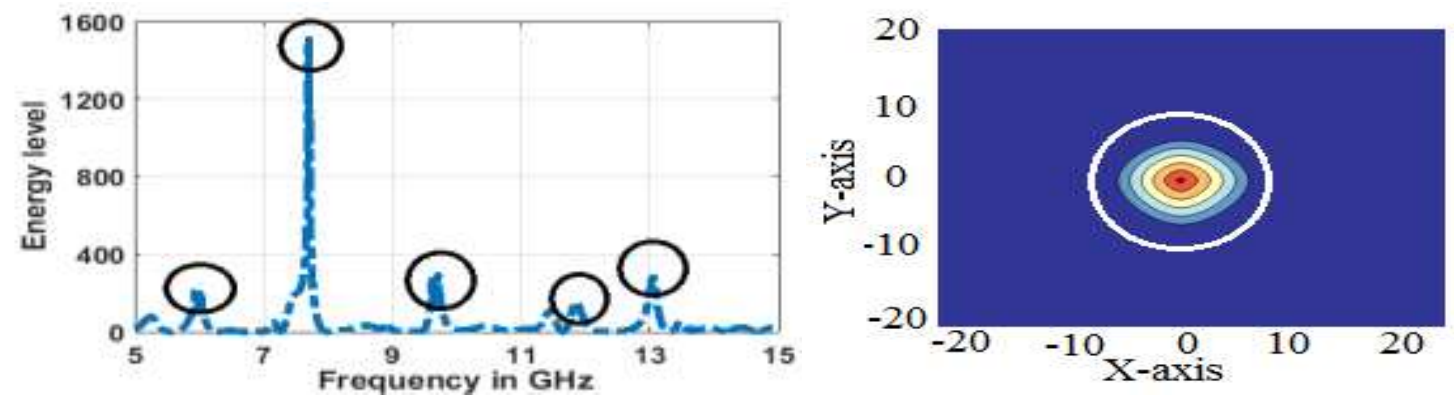

(a) (b)

Figure 14:By DMAS algorithm (a) Energy versus frequency plot(b) Image reconstructed in x-y plane

The efficiency of the proposed DRA for microwave imaging applications is verified by comparing its performance with some exiting DRA designs in terms of size, operating frequency, imaging techniques and experimental validation are as given in table 2. In the reported work, the researchers purposed a complex and large sized DRA $[14-18,20]$ for microwave imaging techniques with only narrow or wider frequency bands. Additionally they did not validate their results experimentally with artificial breast phantom [14-20].The proposed DRA is simple in structure, small in size and provides UWB characteristic. It detects the presence of breast tumor by reconstructing a 2D image in MATLAB. As well its simulated results are also verified by placing the fabricated DRA over artificial breast 
phantom. Hence the proposed research work is one step ahead of the existing research work in the area of imaging and can be effectively used for suggested biomedical applications.

Table 2: Comparison of the proposed DRA with existing antennas

\begin{tabular}{|l|l|l|l|c|l|}
\hline Reference & Structure of DRA & Size in $\mathrm{mm}^{2}$ & $\begin{array}{l}\text { frequency } \\
(\mathrm{GHz})\end{array}$ & $\begin{array}{c}\text { Imaging } \\
\text { type }\end{array}$ & Conclusion \\
\hline 14 & Rectangular DRA & $122.69 \times 122.69$ & $2.8-4.42$ &.$\cdot$ & $\begin{array}{l}\text { Complex structure with larger } \\
\text { size }\end{array}$ \\
\hline 15 & Stacked DRA & $40 \times 40$ & $7.45-11.6$ & $\begin{array}{c}\text { Multi- } \\
\text { statically }\end{array}$ & $\begin{array}{l}\text { Non-planar design and quite } \\
\text { complex due to multi-static MWI }\end{array}$ \\
\hline 16 & L-shaped DRA & $44 \times 44$ & $3.7-9.35$ &.. & $\begin{array}{l}\text { Designed for medical applications } \\
\text { but not demonstrate their results } \\
\text { practically. }\end{array}$ \\
\hline 17 & $\begin{array}{l}\text { DRA array with C- } \\
\text { shaped feed }\end{array}$ & $50 \times 50$ & $\begin{array}{l}4.15-7.2 \text { and } \\
9.35-17.2\end{array}$ &.$\cdot$ & $\begin{array}{l}\text { large in size, experimental testing } \\
\text { with breast phantom is not done }\end{array}$ \\
\hline 19 & $\begin{array}{l}\text { Square shaped DRA } \\
\text { with L shaped feed }\end{array}$ & $70 \times 48$ & $6.12-7.43$ &.. & $\begin{array}{l}\text { Provides high gain with narrow } \\
\text { bandwidth. Experimental testing } \\
\text { is not done. }\end{array}$ \\
\hline 20 & $\begin{array}{l}\text { 4-line fed rectangular } \\
\text { DRA }\end{array}$ & $30 \times 30$ & $24-27$ & $\begin{array}{l}\text { Mono- } \\
\text { statically }\end{array}$ & $\begin{array}{l}\text { Provides AR<3dB, high gain but } \\
\text { with complex design. }\end{array}$ \\
\hline $\begin{array}{l}\text { DRA array with } \\
\text { microstrip feed }\end{array}$ & $35 \times 50$ & $12-18$ & $\begin{array}{l}\text { Only purposed a DRA for } \\
\text { microwave applications but not } \\
\text { done experiment with artificial } \\
\text { phantom }\end{array}$ \\
\hline $\begin{array}{l}\text { Proposed } \\
\text { antenna }\end{array}$ & $\begin{array}{l}\text { Staircase shaped DRA } \\
\text { with DGS }\end{array}$ & $25 \times 30$ & $5.1-15$ & $\begin{array}{l}\text { Mono- } \\
\text { statically }\end{array}$ & $\begin{array}{l}\text { Provides AR<10dB,high gain, } \\
\text { simple structure, 2D of breast is } \\
\text { constructed, experimentally tested } \\
\text { with artificial breast phantom and } \\
\text { safe radiation exposure. }\end{array}$ \\
\hline
\end{tabular}

\section{Conclusion}

This research article presents a MRMWI for the detection of breast tumor using an UWB DRA sensor. For this purpose staircase DRA has been designed and simulated in CST 2016. It has an operating frequency range of 5.1$15 \mathrm{GHz}$, high peak gain of $5.98 \mathrm{~dB}$ (simulated) and dual polarization behavior (AR $<10 \mathrm{~dB}$ ) for $5.12-8.2 \mathrm{GHz}$ and $11.02-13.8 \mathrm{GHz}$ frequency bands. In MRMWI procedure, DRA is rotating around the breast phantom at different focal positions with fixed interval of $10^{\circ}\left(0-180^{\circ}\right.$ in elevation and $0-360^{\circ}$ in azimuthal plane). And transmit the signals towards it that has three different layers as skin, fat and tumor with different electrical properties. After that backscattered signals are recorded (for both cases: without and with placement of breast tumor inside phantom) by rotating the same DRA. For practical testing, the similar procedure is followed by the fabricated DRA and artificial breast phantom. And different backscattered signals are recorded on VNA. These recorded data is processed further for DAS and DMAS data independent imaging algorithms and 2D images are reconstructed in MATLAB from which we clearly observe the position of breast tumor. And it is observed that the DAS algorithm detects the breast malignancies but with the poor image quality. To overcome the drawbacks of DAS the DMAS algorithm was introduced that not only improves the image quality but also provides accurate localization of the tumor.

\section{Declaration}

I confirm that all authors of the manuscript have no conflict of interests to declare.

\section{References}

1. Morrow M, Waters J, Morris E. MRI for breast cancer screening, diagnosis, and treatment. The Lancet. 2011; 378(9805):1804-1811. 
2. Patel BK, Garza SA, Eversman S, et al. Assessing tumor extent on contrast-enhanced spectral mammography versus full-field digital mammography and ultrasound,Clinical imaging. 2017; 46:78-84.

3. Bohra S, Shaikh T.UWB Microstrip Patch Antenna for Breast Cancer Detection. International Journal of Advanced Research in Electronics and Communication Engineering. 2016:5:88-91.

4. Karli R, Ammor H, El Aoufi J. Miniaturized UWB microstrip antenna for microwave imaging. WSEAS transactions on information science and applications. 2014; 11:214-220.

5. Lazaro A, Villarino R, Girbau D. Design of Tapered Slot Vivaldi Antenna for UWB Breast Cancer Detection. Microwave and Optical Technology Letters. 2011:53:639-643.

6. Kaur G, Kaur A. Breast tissue tumor detection using "S" parameter analysis with an UWB stacked aperture coupled microstrip patch antenna having a "+" shaped defected ground structure. International Journal of Microwave and Wireless Technologies. 2020;12(7):635-651.

7. Klemm M, Craddock IJ, Leendertz JA, et al. Radar-based breast cancer detection using a hemispherical antenna array-Experimental results. IEEE transactions on antennas and propagation. 2009; 57(6):1692-1704.

8. Mahmud M, Islam M, Misran N,et al. Ultra-wideband (UWB) antenna sensor based microwave breast imaging: A review. Sensors. 2018; 18(9):2951.

9. Shahira Banu M A, Vanaja S, Poonguzhali. S. UWB Microwave Breast Cancer Detection Using SAR.International Journal of Advanced Electrical and Electronics Engineering. 2013; 2:87-92.

10. Adnan S, Abd-Alhameed RA, See $\mathrm{CH}$, et al. A compact UWB antenna design for breast cancer detection. PIERS online. 2010; 6(2):129-132.

11. Al-Zuhairi DT, Gahl JM, Al-Azzawi A, et al. Simulation Design and Testing of a Dielectric Embedded Tapered Slot UWB Antenna for Breast Cancer Detection. Progress In Electromagnetics Research C. 2017;79:1-15

12. Mozaffarzadeh M, Hariri A, Moore C, et al. The double-stage delay-multiply-and-sum image reconstruction method improves imaging quality in a LED-based photo-acoustic array scanner. Photo acoustics. 2018; 12:2229.

13. Mobashsher Ahmed Toaha .Wideband Microwave Imaging System for Brain Injury Diagnosis,A thesis submitted for the degree of Doctor of Philosophy at The University of Queensland, 2016:145.

14. Abas Sabouni. Dual-Polarized,Broadside,ThinDielectricResonator Antenna for Microwave Imaging IEEE antennasandwirelesspropagation letters. 2013;12:380-383.

15. Huang W, Kishk AA. Compact dielectric resonator antenna for microwave breast cancer detection. IET microwaves, antennas \& propagation, 2009; 3(4):638-644.

16. Suwanta, P., P. Krachodnok, and R. Wongson. Wideband inverted L-shaped dielectric resonator antenna for medical applications.In 2017 IEEE International Conference on Computational Electromagnetics (ICCEM), pp. 188-189. IEEE, 2017.

17. Gupta A, Reddy S, Gangwar RK. Dielectric resonator antenna array for X-band and microwave imaging applications. Microw Opt Technol Lett. 2018;60:960-965.

18. RanaBiswarup, Kumar Susanta .Microstrip Line Fed Wideband Circularly-Polarized Dielectric Resonator Antenna Array for Microwave Image Sensing Microwave/millimeter wave sensors.2017;1(3):1-4.

19. Singhwal Umer Singh, Kanaujia Binod Kumar, Singh Ajit, et al. Novel circularly polarized dielectric resonator antenna for microwave image sensing application. Microwave Optical Technology Letters. 2019;61(7):18211827.

20. NawazHamza, Kiyani Arslan. Ku-band dielectric resonator antenna array for microwave imaging. Microwave and optical technology letters .2016;58(7):1651-1655. 
Figures
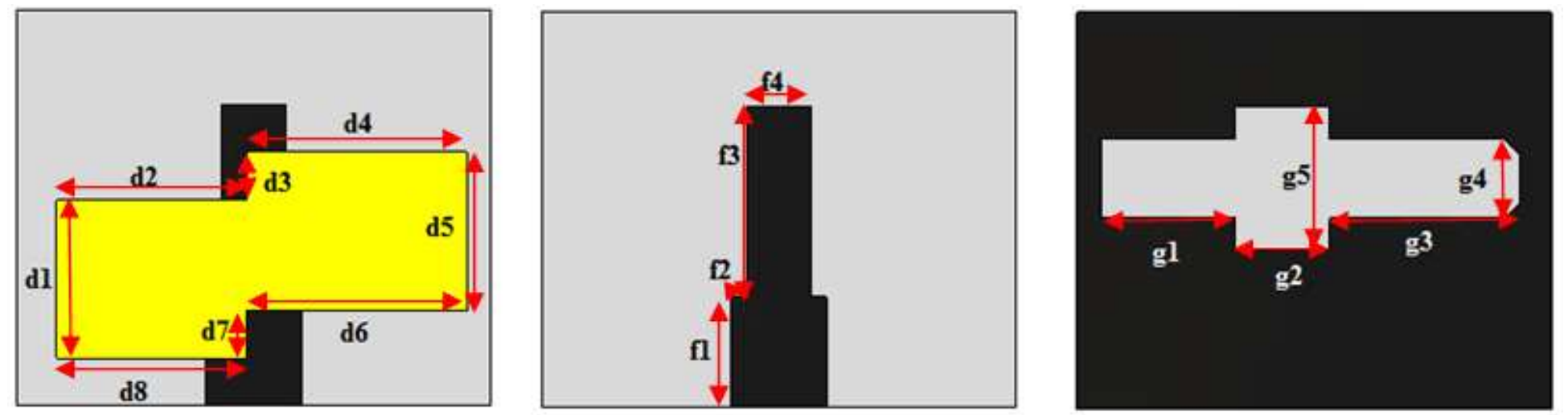

Figure 1

Different layers of the proposed DRA(a) Top view along with DR (b) Feedline(c) Ground plane

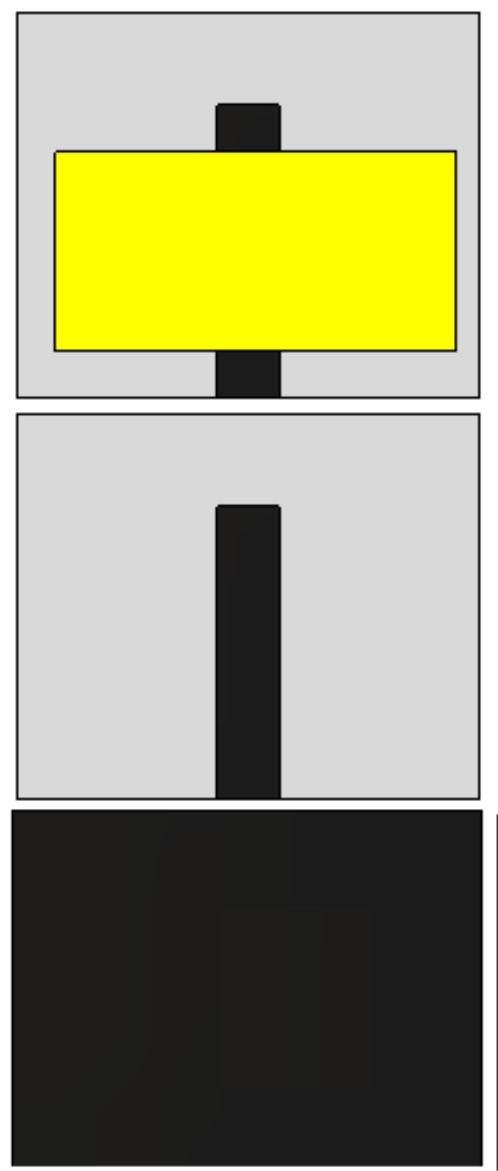

DRA 1
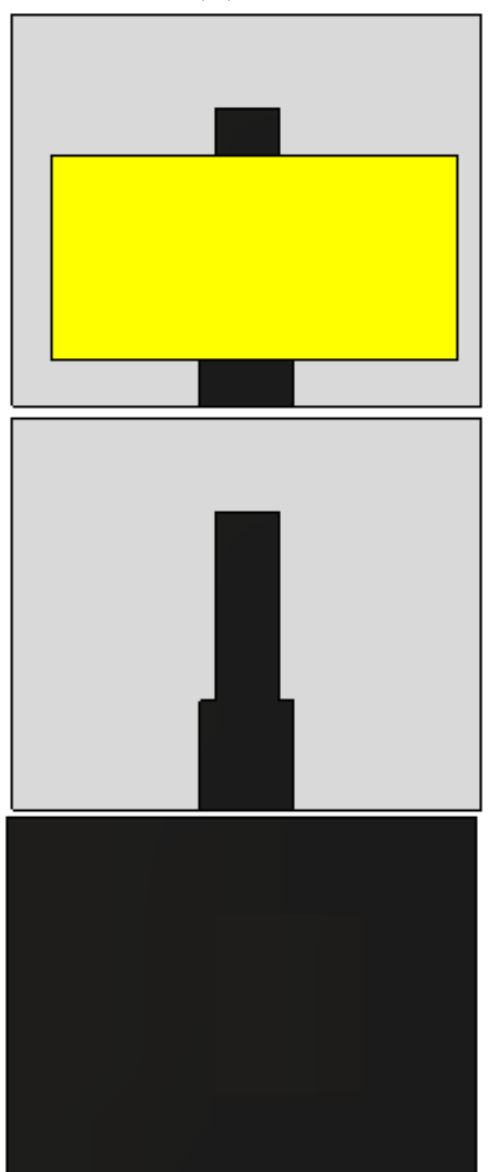

DRA 2
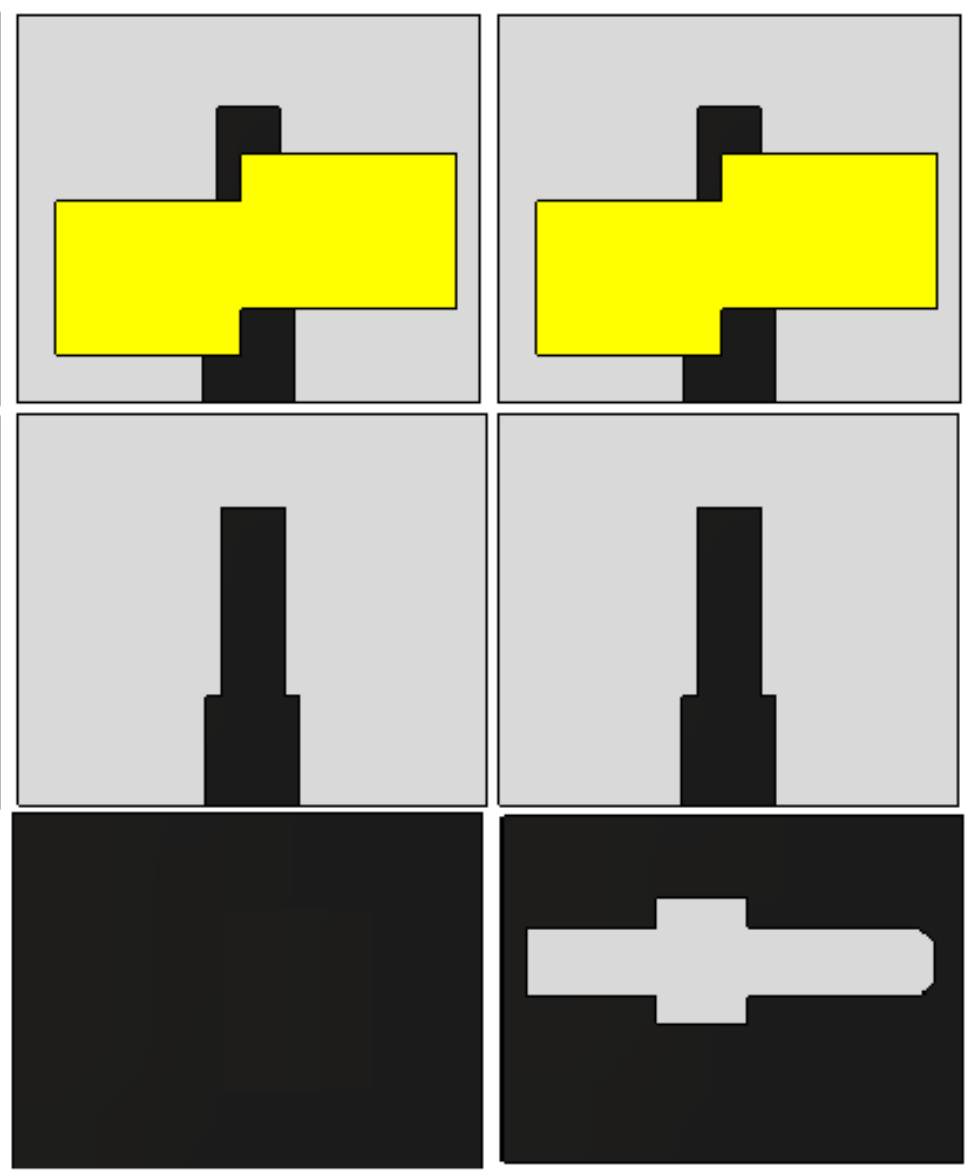

DRA 3

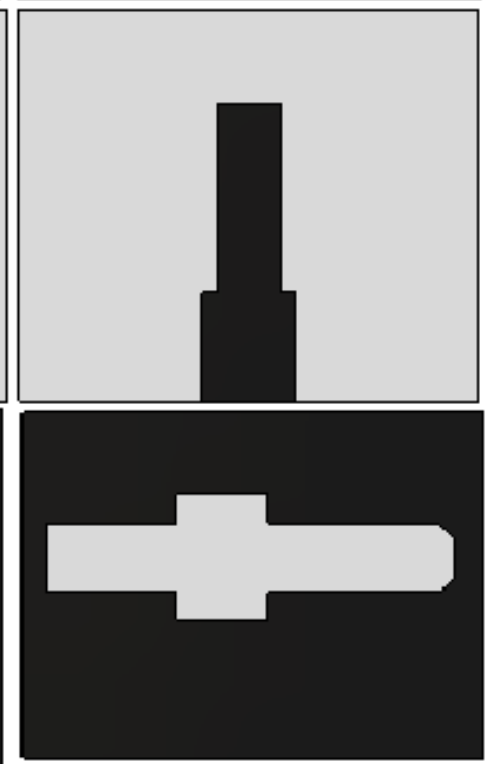

DRA 4

Figure 2

Intermediate geometry of the DRA 


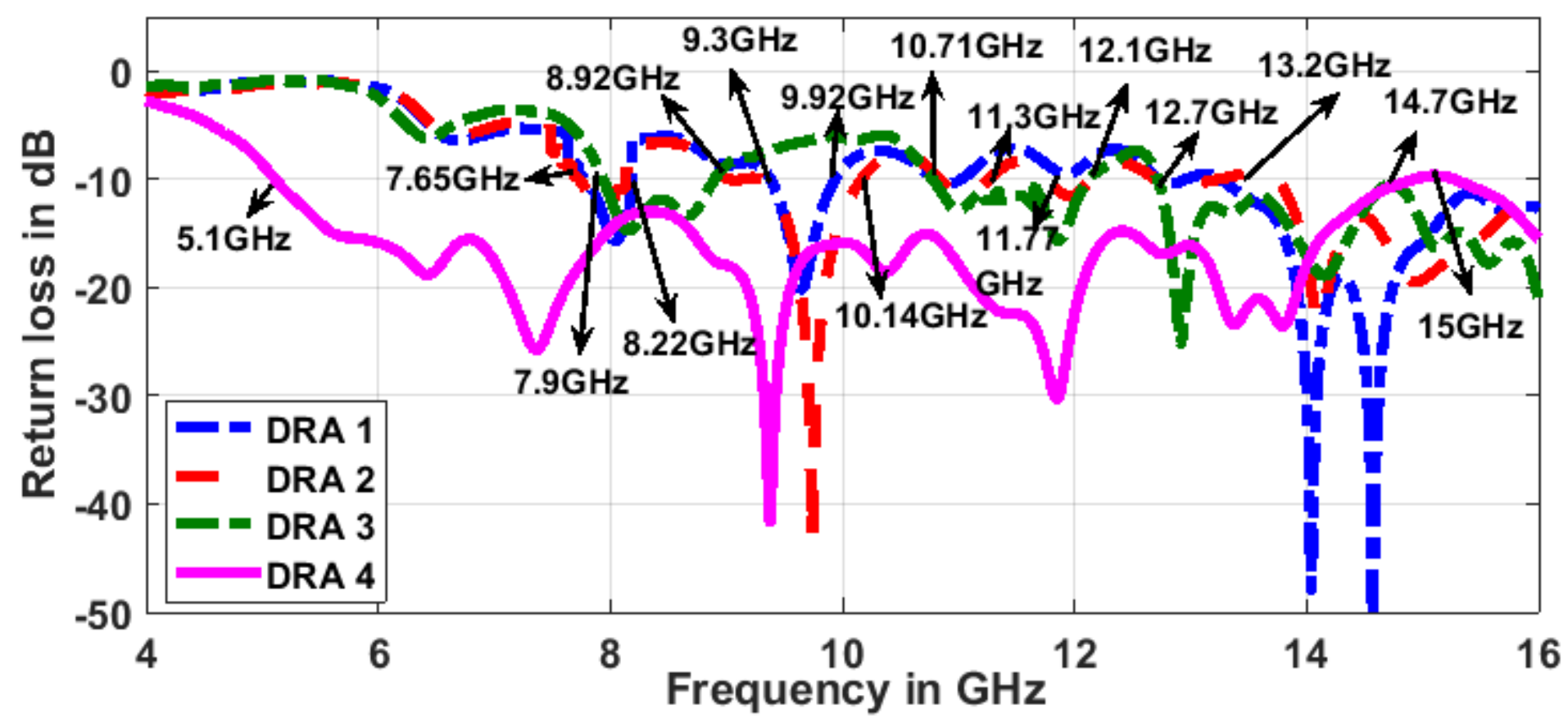

Figure 3

S-parameter responses corresponding to DRA geometries as shows in figure2

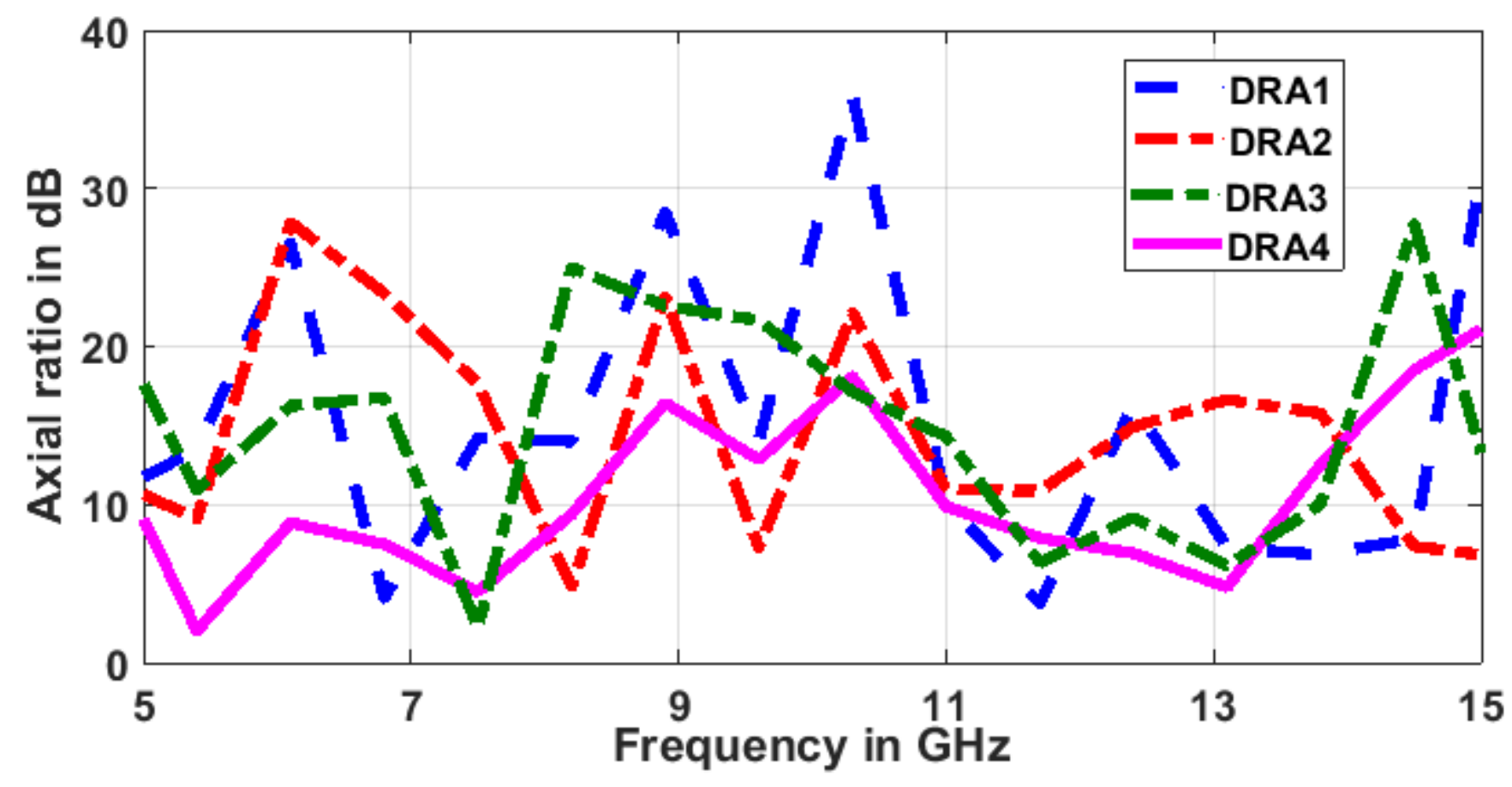

Figure 4

Comparison plot in terms of axial ratio 

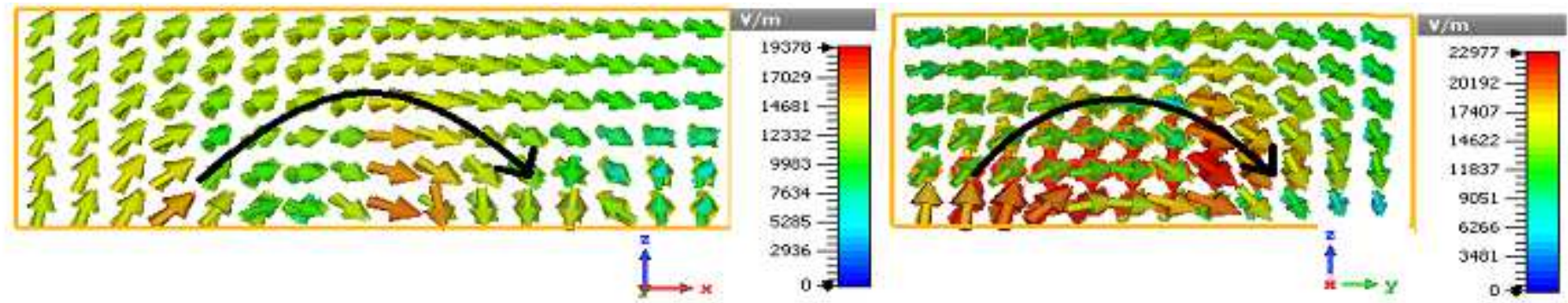

(a)
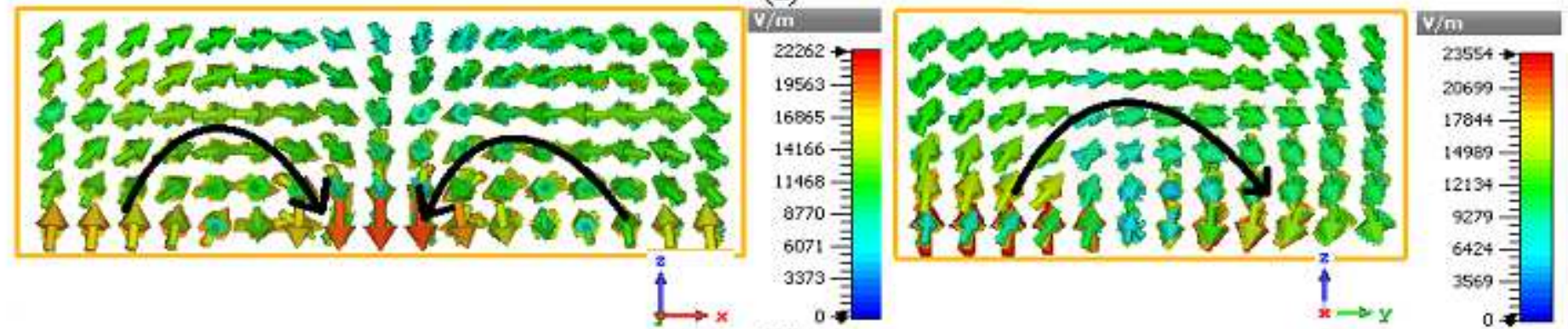

(b)
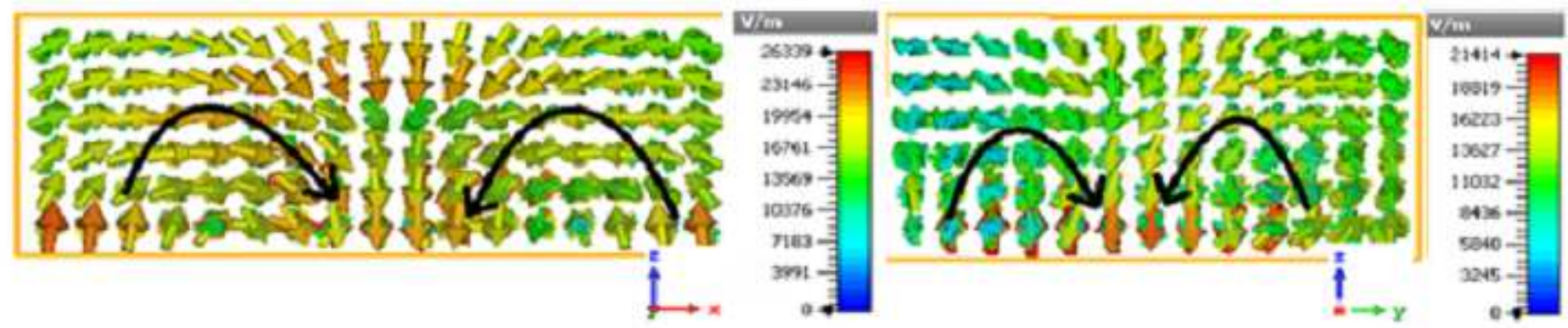

(c)

\section{Figure 5}

E-field distribution plot in XZ and YZ planes for different operating modes (a)TE111(b)TE211(c)TE221

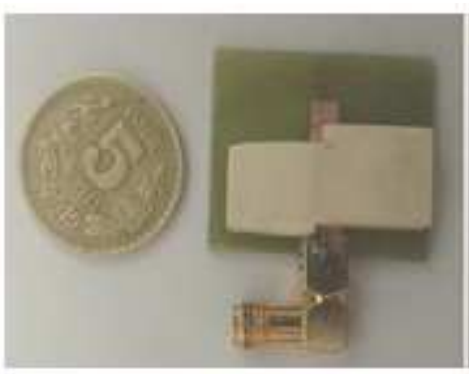

(a)

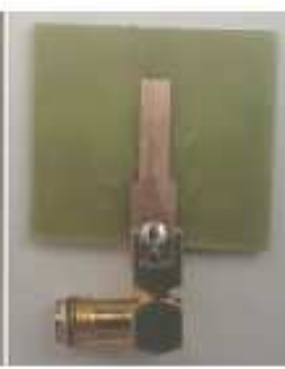

(b)

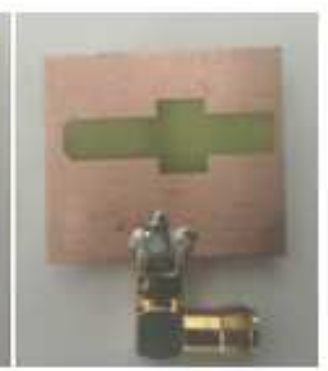

(c)

Figure 6

Fabricated prototype (a) Staircase DR (b) Feedline (c) Ground structure 

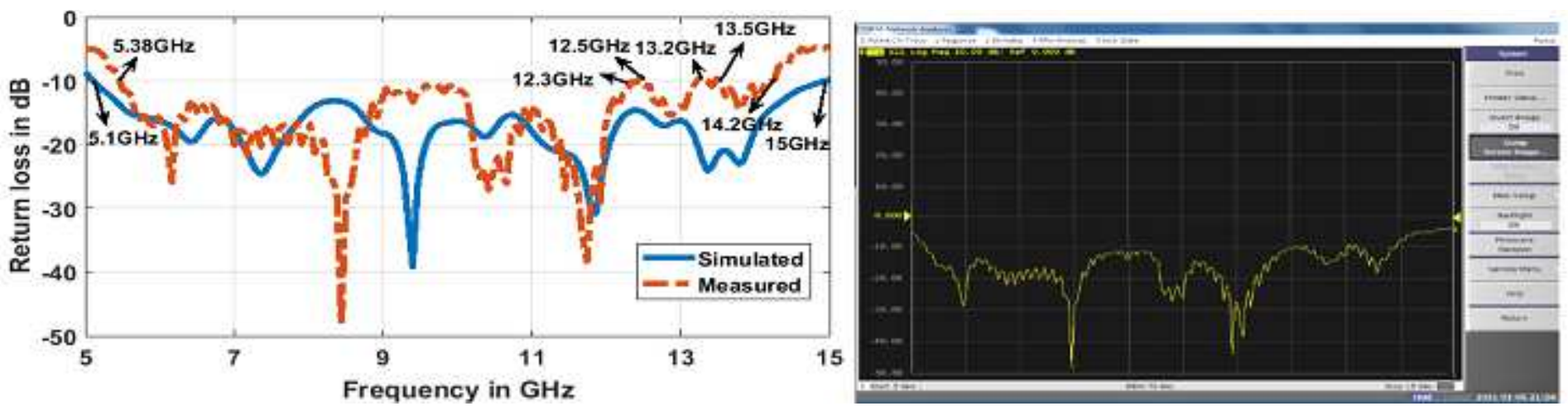

Figure 7

(a) Comparison plot of simulated and experimentally tested S11 result (b) Snapshot of S11 on VNA

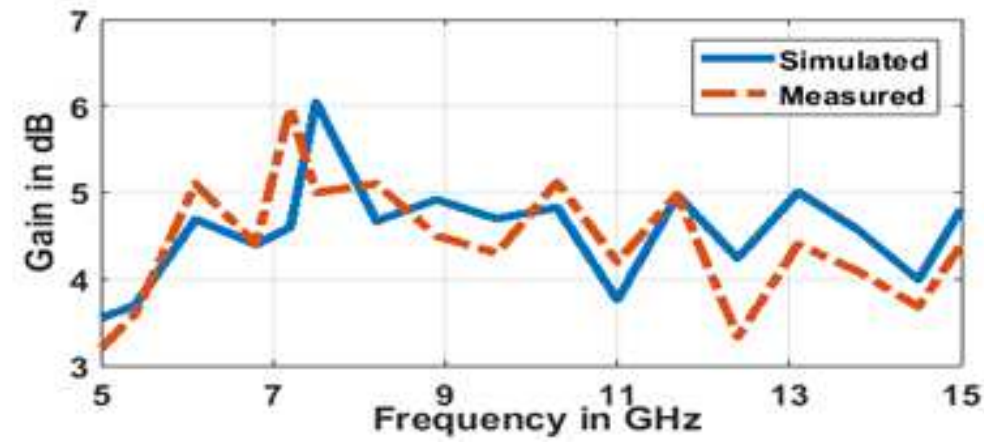

Figure 8

Combined plot of simulated and measured results in terms of gain

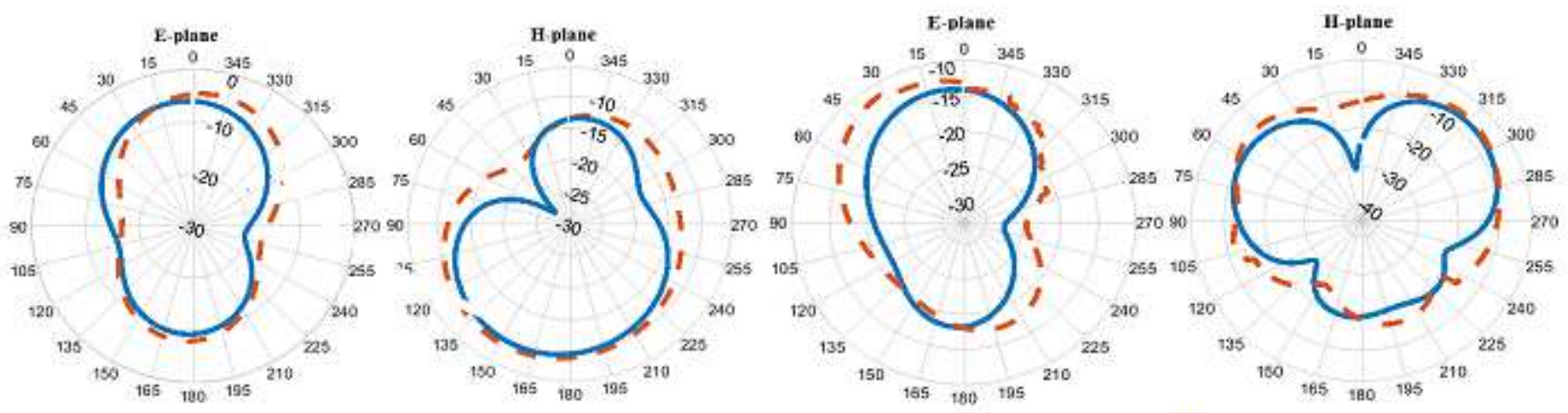

(a)

(b)

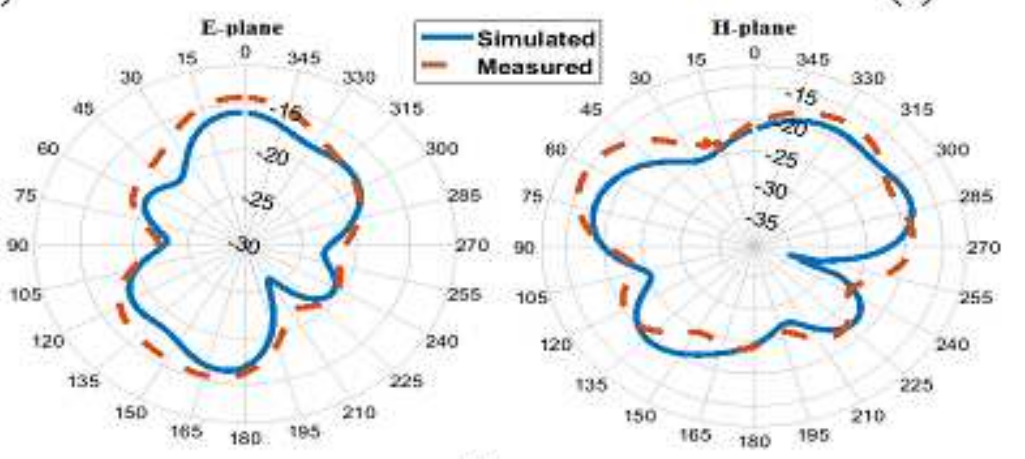

(c)

Figure 9 
Radiation properties in E and $\mathrm{H}$ plane at resonant frequencies of (a) $7.3 \mathrm{GHz}$ (b) $9.37 \mathrm{GHz}$ (c) $11.8 \mathrm{GHz}$

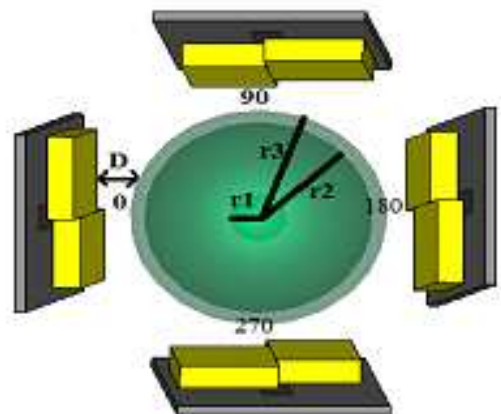

(a)

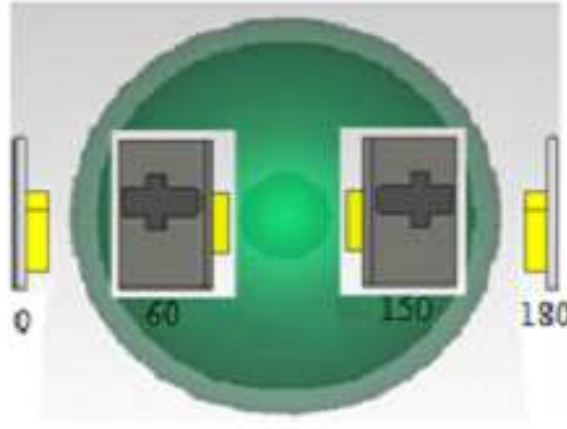

(b)

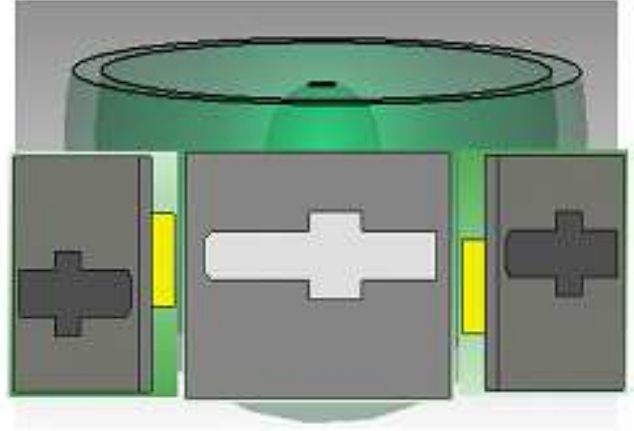

(c)

\section{Figure 10}

Placement of the antenna around phantom (a) Top view (b) Elevation plane(c) Azimuthal plane

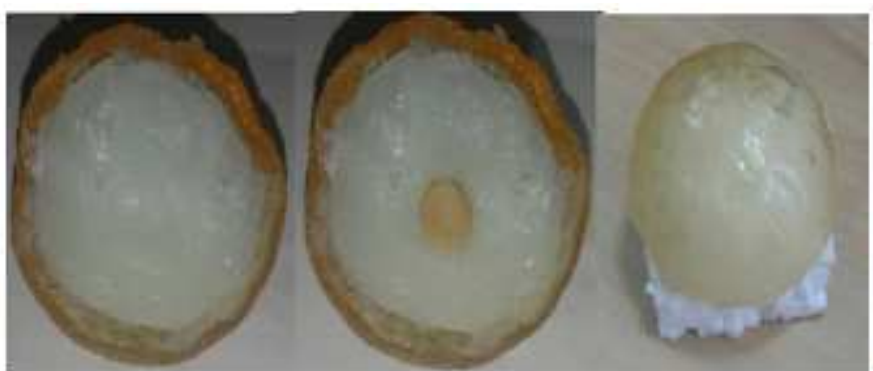

(a)

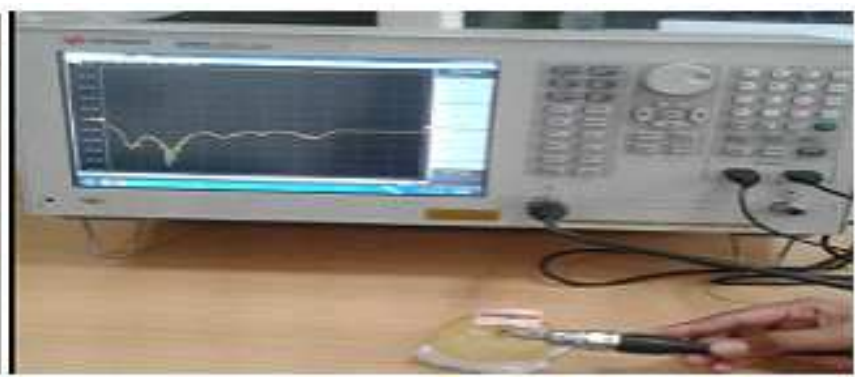

(b)

\section{Figure 11}

(a) Artificial breast phantom with and without placement of tumor (b) Testing on the VNA by placing DRA over the phantom

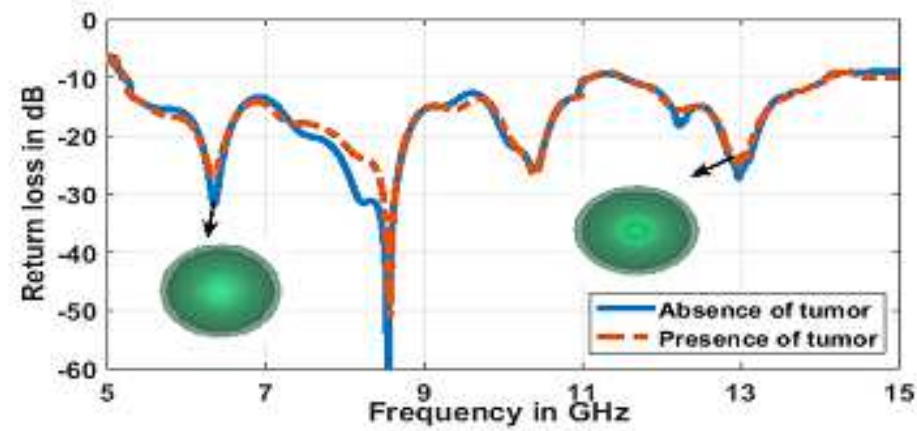

(a)

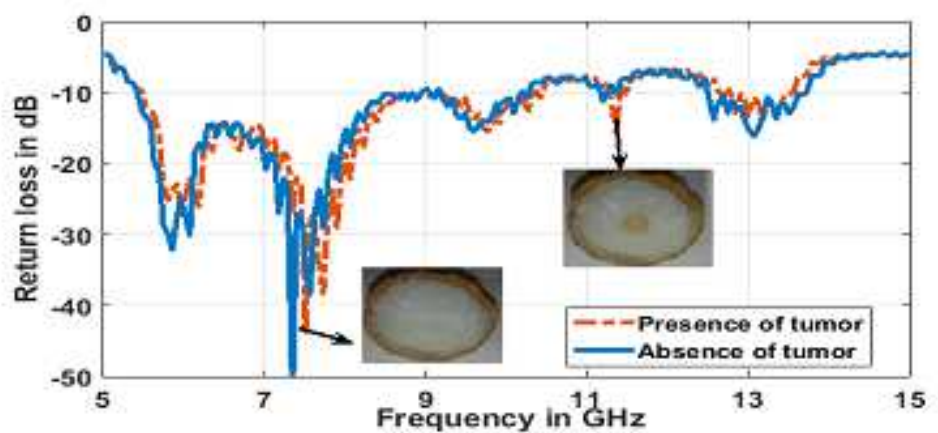

(b)

Figure 12

S-parameters comparison plot with presence and absence of tumor (a) Simulated (b) Measured Results 


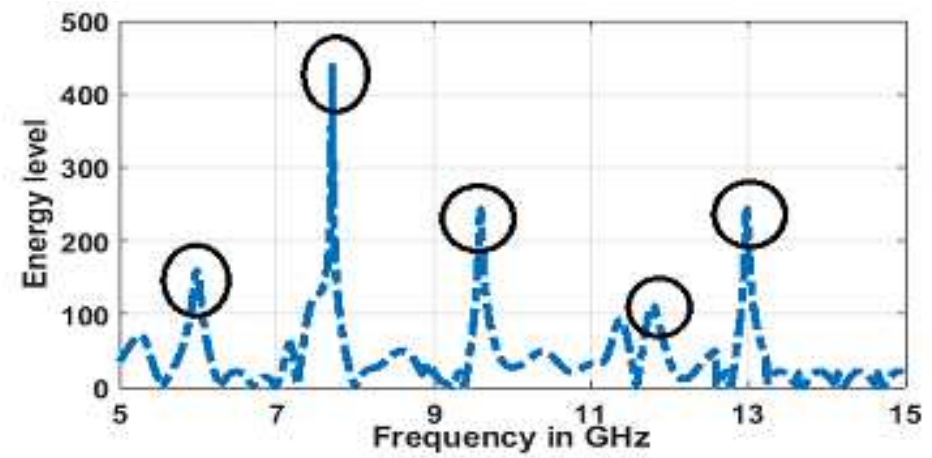

(a)

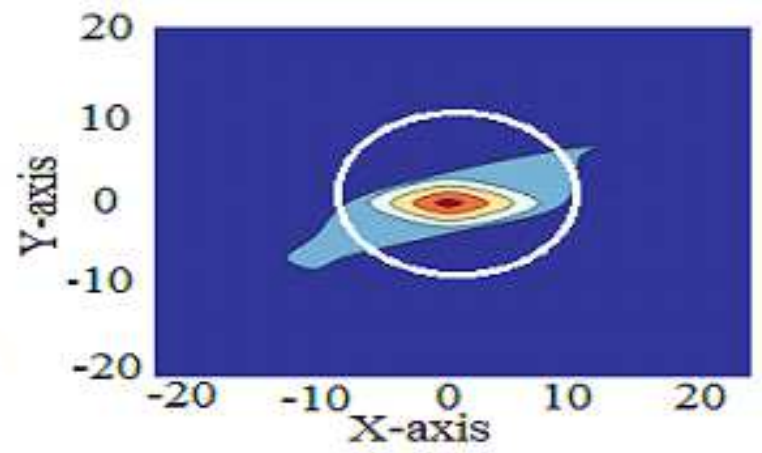

(b)

\section{Figure 13}

By DAS algorithm (a) Energy versus frequency plot (b) Image reconstructed in $x-y$ plane

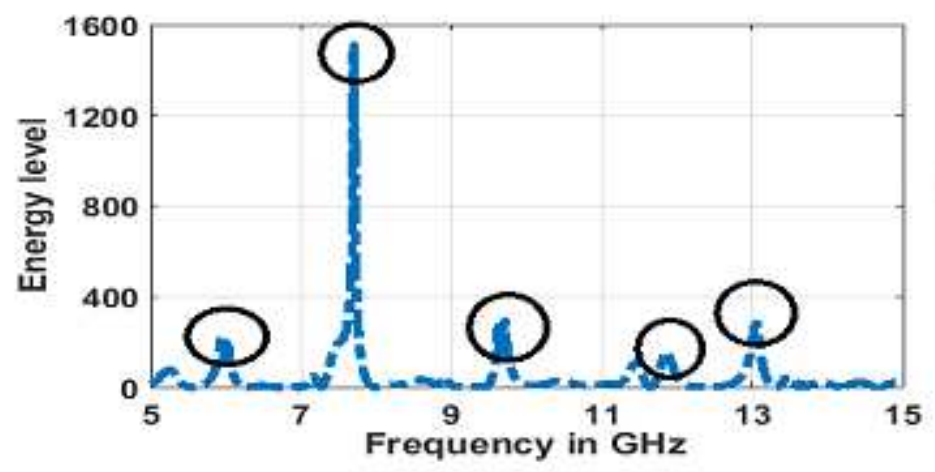

(a)

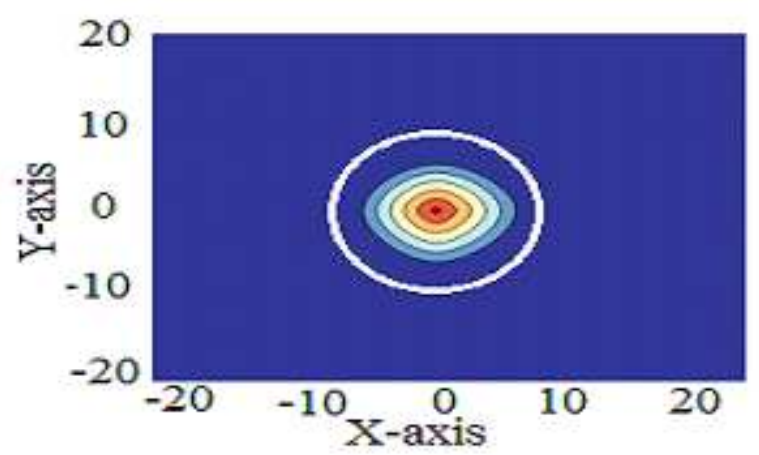

(b)

Figure 14

By DMAS algorithm (a) Energy versus frequency plot(b) Image reconstructed in $x-y$ plane 